\title{
LOS BOTICARIOS DEL HOSPITAL REAL DE SANTIAGO DE COMPOSTELA EN EL SIGLO XVIII
}

\author{
J. Santiago Sanmartín Miguez \\ Depto. de Farmacia y Tecnología Farmacéutica. \\ Universidad de Santiago de Compostela.
}

\begin{abstract}
RESUMEN
El presente trabajo trata de dar a conocer la vida y la actividad de los profesionales de la Botica de un emblemático hospital español durante el siglo XVIII. Este Centro sanitario, fundado por los Reyes Católicos en las postrimerías del siglo XV, dotará a los profesionales de la Botica de unas originales Constituciones que regularán la vida de estos más allá de su tarea farmacéutica. El autor intenta recrear la figura de los Boticarios de la Institución en su vertiente profesional y la que deriva de ésta en el conjunto de la sociedad urbana de su época; para ello se estudian, en distintas secciones, las obligaciones de los Boticarios en tanto que técnicos del medicamento y en su condición de Ministros Mayores del Establecimiento, su engranaje en el entramado sanitario del Centro y los conflictos que aparecen entre los diversos estamentos, su formación, sus sueldos - que se comparan con el de otros profesionales afines y aún con los de otros Hospitales españoles de similares características-, los criterios de su nombramiento así como el origen y la consideración social que su cargo les depara.
\end{abstract}

\section{SUMMARY}

The present work tries to illustrate the life and work of the professionals of a Pharmacy at an outstanding Spanish hospital in the 18th century. This centre, founded by the Catholic King and Queen (Fernando of Aragón and Isabel of Castilla) in the late 15th century, will provide the professionals of Pharmacy with an original constitution that shall rule their lives beyond their pharmaceutical activity. The author aims to recreate the figure of the Institution's Pharmacists, both on their professional aspects and on their projection on the urban society of their time. To do so, different sections focus on the obligations of the Pharmacists as drugs technicians and as Major Ministers of the Institution; Their interaction among the centre sanitary personnel and the conflicts that arise among the different professionals; their formation; their salary — which is compared to those of similar professionals and even with those of other similar Spanish hospitals-, the criteria for their promotion as well as their social origin and consideration their job gives them.

\section{INTRODUCCIÓN}

El Hospital Real de Santiago fue fundado por los Reyes Católicos en el año 1499 con la finalidad de acoger a los numerosos peregrinos que desde toda Europa acudían 
votivamente a visitar el sepulcro del Apóstol Santiago el Mayor. Esta misión de acogida, prontamente fue complementada por otra sanitario-asistencial con la que continuó hasta mediado el siglo XX.

A la dotación médico-quirúrgica, que desde el primer momento precisó la Pía Institución, se le añadieron los indispensables servicios farmacéuticos, con la creación de una botica propia, que estuvo operativa desde los primeros momentos y permaneció hasta 1880, año en que se suprime, para pasar a abastecerse de otras farmacias de la ciudad. El servicio de la botica estaba en principio dirigido a los enfermos hospitalizados, a los empleados del Hospital, a los niños expósitos de la inclusa con que contaba el Establecimiento, a los pobres de la ciudad que solicitaban de sus servicios y a los peregrinos enfermos que llegaban a sus puertas. Sin embargo, durante algunos períodos de su historia la farmacia fue pública, de modo, que cualquier particular podía abastecerse de los medicamentos que en ella se preparaban, previo pago de los correspondientes honorarios regulados mediante una tarifa oficial. Se trataba sin duda de una farmacia de primer orden, a tenor de los recetarios e inventarios que de ella hemos estudiado, perfectamente dotada en cuanto a la preparación técnica de sus profesionales y al utillaje y materiales en ella presentes en cada momento de su dilatada historia.

La actividad de la botica, como la de toda la vida hospitalaria, viene determinada por una serie de disposiciones legislativas que se sucederán a lo largo de los años. En primer lugar, por su rango, hay que considerar las sucesivas Constituciones que se otorgaron al Hospital; estas son tres, las iniciales fueron dictadas por el Emperador Carlos V en el año 1524, en ella se dan las primeras instrucciones para el ordenamiento de la botica - aunque esta estaba ya operativa desde al menos trece años antes. Siguieron a estas las de Felipe II, del año 1590, especialmente interesantes por entrar en materia detallada referida a la Farmacia. En 1804, el Rey Carlos IV promulga las últimas Constituciones para el régimen y Gobierno del Hospital. A este primer grupo de normas, y aunque de naturaleza diferente, hay que añadir — dada su importancia - los Mandatos de Visita dados por Carlos II en 1697, aunque aprobados y confirmados en 1700 .

La estructura de la Institución se concibe desde su fundación a modo de un cenobio, resultante del frustrado deseo de convertir el Monasterio Benedictino de San Martín Pinario de Santiago en centro sanitario principal de la ciudad. Es preciso tener muy presente esta intencionalidad para comprender el deseo de los legisladores de hacer participar a los Oficiales de la Casa en una serie de actividades comunitarias que nada tienen que ver con su cometido profesional. Este régimen de comunidad, al persistir en el siglo XVIII cuando entre en crisis el modelo institucional tradicional, planteará no pocos conflictos ${ }^{1}$.

1 García Guerra, D. (1983), El Hospital Real de Santiago de Compostela (1499-1804), p. 155. 
En este trabajo, que es fruto básicamente del análisis de la documentación que relativa a la Pía Institución se conserva en el Archivo Histórico Universitario de Santiago, Serie Hospital Real (AHRC) - y que durante los últimos tres años he estado revisando para la elaboración de mi Tesis Doctoral-, vamos a ver la actuación de los Boticarios bajo los aspectos que afectan a sus relaciones personales dentro del Centro, así como a sus funciones en el entramado sanitario del Hospital.

\section{EL PERSONAL DE LA BOTICA}

Siendo el objetivo de este artículo conocer la actividad de los boticarios de la Pía Institución, junto a ellos, habrá que prestar también atención a quienes gozando de esa titulación desempeñan el cargo de Ayudantes; al mismo tiempo habremos de considerar las relaciones que en función de su tarea, estos profesionales mantienen con otros Oficiales directamente relacionados con los servicios farmacéuticos.

A lo largo del período que abarca nuestro trabajo, la botica del Hospital apenas sufre variación en lo que a su número de empleados se refiere; tampoco se experimentan cambios en sus obligaciones ni en su relación mutua, y en este sentido, lo que de ellos se dice en el año 1701, es igualmente válido al final de la centuria. La organización de la botica aparece perfectamente estructurada ya en los primeros tiempos de su andadura. Esta estructura laboral, con Boticario, Oficial y Mozo - aunque variable en sus denominaciones - permanecerá inalterable hasta $1880^{2}$, año en que la farmacia del Hospital dejará de existir como tal. Vamos a considerar las circunstancias de este personal adscrito a la oficina desde dos vertientes, la profesional y la puramente humana; esta segunda faceta va a presentar unas características muy especiales, como especial es el ámbito en que se desenvuelve su vida y su actividad. Efectivamente, se da en la reglamentación que atañe a los Ministros y Oficiales la doble intención de enmarcar su actividad profesional y la de regular su aportación a la vida comunitaria de la Casa. Esta circunstancia, que llama la atención a los ojos del observador actual, no es sorprendente en la España de la decimosexta centuria, que es cuando se crean las bases constitucionales que subsistirán en el siglo XVIII. El marcado carácter religioso que rige toda actividad en esa época se mantendrá por algún tiempo más. No obstante, la vigencia de una normativa anacrónica, chocará con el espíritu progresivamente secularizado que campea sobre el siglo XVIII.

A continuación vamos a dar cuenta del cometido que se le asigna a cada uno de los profesionales que trabajan en la botica, incluyendo algunas actuaciones concretas que se dan a lo largo del período que estudiamos.

2 En los años finales de la existencia de la Farmacia aparecerá la figura del Boticario segundo, del que conocemos únicamente dos nombres. 


\section{El Boticario}

Aunque tengamos que aguardar hasta 1524 para conocer lo que las disposiciones legales otorgan y esperan del boticario, sabemos que en 1511 Guillén de Briviesca estaba ejerciendo ese cargo en el recién estrenado edificio ${ }^{3}$. Desde el momento en que constatamos la presencia de boticario en la Real Obra, estamos en condiciones de conocer una serie de circunstancias que condicionan su quehacer diario. El boticario es, por su cargo, Oficial principal de la Casa; posteriormente se confirmará su condición de Ministro, lo que llevará aparejado una serie de obligaciones, por ejemplo, la de asistir a determinadas celebraciones religiosas. De ello se da mandato en la Carta de Fundación del Hospital de 1504; se ordena que el boticario, como Oficial, debía participar en la vigilia de la festividad de Santiago, en la propia Fiesta del Apóstol, así como en la conmemoración de su Traslación. Tal normativa continúa vigente en el setecientos. Igualmente, en las festividades de Todos los Santos y Difuntos, estaban obligados a la asistencia a los oficios y a la Misa de Réquiem que se aplicaba por las ánimas de los Reyes y fallecidos en el Hospital.

Con la promulgación de las Constituciones de Carlos V en 1524, se especifican ya detalladamente las obligaciones y derechos del boticario de la Institución. Las de Felipe II acotan aún más sus atribuciones; ni en unas ni en otras se mencionan los empleos de oficial de botica, ni del mozo, y sin embargo, hemos visto que ambos están operando desde época temprana.

Como Ministro Mayor del Hospital, el boticario tiene voz y voto en los Cabildos. Estas reuniones se realizan con periodicidad muy variable y se convocan para tratar algún asunto puntual de especial importancia como puede ser la toma de posesión de un Ministro Mayor, etc. En aquellos Cabildos en que se precisa de un debate y votación para la toma de una decisión, el boticario participa por turno, al igual que el resto de los Ministros. Respecto a la frecuencia de los Cabildos, en ocasiones son mensuales mientras que en otras no se realizan más que una vez por año; lo habitual en el siglo XVIII es que tengan una convocatoria trimestral de promedio.

Vamos a considerar a continuación lo que podríamos denominar la «cotidianidad» del quehacer profesional del farmacéutico. Lo vamos a hacer de forma somera, dado que la mayor parte de la información que disponemos a este respecto se ofrece en los respectivos apartados de este trabajo, no como hechos centrales, sino complementarios a las diferentes circunstancias que conforman la casuística de la vida de la botica $\mathrm{y}$ de sus profesionales.

En principio, hay que diferenciar dos posibilidades: la primera será la que a través de las diferentes legislaciones marcan la rutina en la actividad de los boticarios y sus auxiliares. Esta actividad es de carácter imperativo; coloquialmente podríamos decir

\footnotetext{
3 AHRC. Escrituras, 2.
} 
que esta actividad «es la que debería ser». Sin embargo, no siempre la praxis farmacéutica -en un entorno sanitario tan complejo y en ocasiones cambiante como es el del Hospital - permite llevar a cabo escrupulosamente las disposiciones legales que reglamentan esa actividad. Ello es así, fundamentalmente, porque frecuentemente dejan de darse las condiciones ideales que se pensaron para el desarrollo de la labor farmacéutica. Así por ejemplo, no se adecua el personal de la botica a las frecuentes oscilaciones del número de enfermos, lo que comporta que, si en ocasiones los profesionales adscritos a la farmacia son más que suficientes, en otros momentos de la vida hospitalaria éstos van a encontrar serias dificultades para atender adecuadamente las obligaciones que las ordenanzas les imponen. A pesar de las posibles carencias coyunturales, que sin duda periódicamente se dan en el suministro de fármacos a los enfermos del Hospital, la botica siempre tuvo capacidad de autoabastecimiento; queremos decir con ello que no hubo necesidad de recurrir a la adquisición de medicamentos en otras oficinas, tal como aconteció en otras instituciones de carácter análogo, como es el caso del Hospital de San Hermenegildo de Sevilla, en cuya botica únicamente se preparaban los remedios más frecuentes, «...al mismo tiempo que se adquiere fuera, en alguna de las boticas privadas establecidas en la ciudad, aquellos (fármacos) que tienen una indicación poco frecuente» ${ }^{4}$. No son pocos, ni en ocasiones cortos, los períodos en los que falta el titular de la botica, por enfermedad, fallecimiento o relevo, tal como informamos en otros apartados. En esos espacios de tiempo se ve reducido el personal, sin que se prevea una sustitución temporal del mismo (excepto en puntuales ocasiones). Por todo ello y por otras circunstancias de menor incidencia, la pretensión de un cumplimiento escrupuloso de las ordenanzas ha de descartarse en buena lógica. De esta manera lo debieron entender los sucesivos rectores de la Obra Pía, ya que son poquísimas las denuncias y menos aún las sanciones que se citan por inobservancia de las Constituciones. Vamos a dar a continuación unas pinceladas de lo que era la práctica real el día a día de la Botica del Hospital.

En 1792 se nos ofrece, por única vez, una información detallada del horario que la botica había de cumplir. La noticia radica en que, ante una reiterada demanda, se produce un reajuste de los salarios así como una regulación de la plantilla, que afecta a distintos oficiales del Hospital ${ }^{5}$. Al tiempo que se accede a este aumento de sueldo, y «...sin perjuicio del buen concepto que merece el actual boticario...», el Administrador le recuerda el cumplimiento de sus obligaciones, a él y al oficial:

«...conservando abierta la Botica desde antes de la visita de la mañana hasta el medio día, y por la tarde también desde antes de la visita hasta la hora de la seis en verano, y la de quatro y media en Ynvierno, y sin faltar su concurrencia en el restante tiempo a subministrar

4 Herrera DÁvila, J.,(1990), Visión Histórico-Sanitaria del Hospital de San Hermenegildo de Sevilla (1455-1837), Tesis Doctoral inédita, Sevilla, p. 309.

5 AHRC. Cédulas Reales, 613. 
lo que se necesite en los casos que ocurran, y se establezca la intervención del Oficial en el recivo y cuidado de Azucar, Aguardiente y aceite,...y se tengan en ella (la Botica), vajo de dos llaves, las partidas que por orden reciban, teniendo una llave el Boticario, y otra el Oficial...».

Como se aprecia, hay fijado un horario de atención al público intrahospitalario y que enmarca el tiempo que el boticario debe permanecer en la oficina atendiendo a las tareas de preparación de las recetas para las salas de enfermos. Pero además, se le dice que el resto del tiempo debe estar localizado y disponible para las urgencias que pudieran presentarse a cualquier hora.

La vida del boticario estaba completamente condicionada por su calidad de Ministro Mayor de la Institución; las sucesivas constituciones y mandatos preveían su dedicación exclusiva y exhaustiva al Hospital: sin embargo, la práctica diaria permitía al farmacéutico una cierta delegación en su auxiliar, y con ello, destinar determinados momentos a su vida privada. Con todo, el farmacéutico fue, en definitiva y a lo largo de los años, un íntegro y eficiente profesional totalmente entregado al Hospital. Su rutina diaria comenzaba muy temprano, como muy temprana era la actividad en la Casa y en la ciudad. Su primer acto obligatorio era la visita a los enfermos en las salas, en compañía de los médicos y cirujano. Esta visita constituía el momento culminante de la vida Hospitalaria. El farmacéutico iba anotando los tratamientos que el médico le dictaba y el enfermo al que se destinaba $\left(n^{\circ}\right.$ de cama). Era frecuente, dado que los dos médicos consultaban simultáneamente, que el mancebo acompañara a uno de ellos. Cierto que ello contravenía las ordenanzas, pero no menos cierto que estas no ofrecieron nunca alternativas a sus propias deficiencias, y por lo tanto era labor de los profesionales solventar mediante una práctica responsable los problemas que se planteaban.

Terminada la visita, de duración variable, el boticario, por mandato constitucional, acompañado del médico, bajaba al zaguán para atender a los enfermos pobres de Santiago y de los alrededores, suministrándoles los preparados oficinales más usuales en cada estación. No se confeccionaban para estos enfermos de consulta externa formulas magistrales, por lo que, en la mayoría de los casos la medicación suministrada era totalmente inespecífica. El aspecto más positivo de esta apresurada visita —no duraba más de un cuarto de hora ${ }^{6}$ - era que posibilitaba el internamiento de alguno de estos enfermos después del examen facultativo.

A la hora de la comida de los enfermos el boticario tenía obligación de estar presente en ella. Por la tarde tenía lugar otra visita a las salas, que sería de características similares a las de la mañana, aunque deteniéndose únicamente en los enfermos que en aquella se señalaran como más precisados de atención, o los que en el intervalo hubieran sufrido un agravamiento. De esta visita vespertina tenemos alguna noticia relacionada con el boticario, como un violento episodio sucedido en 1714, del que

6 Constituciones de Carlos V. 1524. No 44. 
hablaremos más adelante, que enfrentó al boticario Antonio Ramos de Solís con el médico Domingo Sanjurxo Arellano. Este suceso nos ilustra respecto a la hora de la visita de la tarde, la una, por lo que también podemos suponer la hora de la comida, que sería en torno a las doce. El resto del tiempo el farmacéutico lo dedicaría a la preparación de las recetas prescritas en las visitas efectuadas ese día. Una parte de las medicaciones realizadas se confeccionaban en grandes cantidades una o dos veces al año; se trataba, como es lógico, de preparaciones de frecuente prescripción y costosa elaboración, que estarían así dispuestas para su consumo en ese largo período. En un escrito fechado en Madrid el 26 de Mayo de 1723, se da fe de que el farmacéutico Ignacio de Arredondo Recamán es requerido en Madrid por la Real Cámara, llamamiento que soslaya aduciendo que tiene mucho trabajo en la botica por realizarse en aquella época las infusiones, confecciones y destilados de aguas para todo el año; esta tarea debió parecer a la Cámara muy importante e inaplazable, por cuanto en efecto se le alzó la orden de acudir a la convocatoria y se le exhorta a que ejerza su oficio en el Hospital.

Otra de las tareas de las que debe ocuparse el boticario es la de marcar las pautas para el cultivo, en la huerta del Hospital, de las especies vegetales que precisará para preparar determinadas medicaciones. El hortelano del Centro debía ajustarse al criterio de aquel en la elección de los cultivos a realizar, siempre en función de las necesidades terapéuticas del momento, la escasez de géneros en los proveedores habituales y las posibilidades de éxito en esos cultivos. Aunque no adscrito a la botica, el hortelano del Hospital tiene una innegable relación con ella; por mandato Constitucional, emanado de las promulgadas por Carlos V en 1524, este profesional estaba encargado de cuidar la huerta aneja al edificio hospitalario y en ella cultivar las hierbas útiles en la botica, fundamentalmente las de difícil adquisición en la ciudad. El espacio destinado a huerta no era ciertamente extenso, la propia Constitución 63, de las antes citadas, la describe como pequeña, de tal forma que se duda entre disponer de un hortelano que se encargue exclusivamente de su cuidado, o encomendar ésta, a tiempo parcial, a persona ajena a la Institución. Aunque imposible de cuantificar, a la vista de los datos disponibles, la incidencia del producto de la huerta en el suministro de géneros a la botica es ciertamente pequeño, considerando el volumen global de los que entran en la misma. Hay también extensas lagunas documentales acerca de la variedad de vegetales que se cultivan en el recinto. La información más rica de que disponemos, que nos da una relación completa de lo que en la huerta se cultiva, así como de las necesidades que deberían cubrirse, hace referencia al último siglo de la actividad de la Farmacia ${ }^{7}$.

La huerta y el hortelano sufren, a lo largo de la historia del Hospital, las lógicas variaciones que dicta la evolución terapéutica por un lado y la política de gestión del

7 AHRC. General, 942. 


\section{J. SANTIAGO SANMARTÍN MIGUEZ}

Centro por otro. Igualmente, la calidad de los que en ella se emplean está sujeta a la misma variabilidad que cualquier otro puesto del organigrama de la Institución.

\section{El Oficial de Botica}

Respecto al Oficial Mayor, llamado en ocasiones «Mancebo de la Botica» y «Ayudante», tiene categoría de Ministro Menor, sin voto en los Cabildos, siendo su elección y nombramiento privativo del Administrador del Hospital. El grado de formación del oficial es variable según los tiempos. En la casuística veremos que esta plaza la ocupa con frecuencia un boticario aprobado, mientras que en otras ocasiones desempeña este empleo, como práctica obligada, un candidato a la obtención de ese título. Miguel Valero, ayudante de botica en 1769, abandona el puesto para establecerse por su cuenta en la misma ciudad de Santiago.

No es precisa la ausencia del titular para ver al mancebo u oficial desempeñando la tarea más específica de aquel, la preparación de los medicamentos. En 1714, con motivo de un conflicto que incumbe al boticario Antonio Ramos de Solís y del que daremos más profusa información en el capítulo que cierra este trabajo, se toma declaración al entonces oficial, cuyo nombre aparece ilegible en el documento, pero del que sabemos que contaba con veintisiete años, y que manifiesta:

\footnotetext{
«...allo en ella (la Botica) al dho D. Antonio Ramos su amo sentado...y habiéndose puesto el que declara a componer las medizinas para los enfermos...» 8
}

Por citar algún caso más de sustituciones llevadas a cabo por el auxiliar, mencionamos la ausencia por abandono no autorizado del titular Ignacio Arredondo y Recamán, que hubo de ser detenido en Pontevedra por un alguacil del propio Hospital en 1730. En aquella ocasión quedó al frente de la botica el oficial mayor Juan Francisco Ramos. Otra causa obligada de quedar el oficial al frente de la oficina era el fallecimiento del boticario y en tanto no se procedía al nombramiento del nuevo titular. Esta norma, regularmente cumplida, presenta alguna excepción que dará lugar a sus respectivos conflictos.

Con el correr del tiempo se pretende un mayor rigor en la atención de la oficina de Farmacia, de modo que únicamente se deja la dirección de la misma a un mancebo en el caso de que este sea ya boticario titulado, aunque ejerciendo funciones auxiliares. Al solicitar la previsible futura vacante por enfermedad del titular, Juan García Cuervo, a la sazón oficial mayor, suplica le sean tenidos en cuenta sus más de veinte años de servicio en la botica, pero hasta que llegue el momento de ocuparla, solicita

8 AHRC. Rentas del Hospital, 1.769. 
«... en interín nombrarle para que sirva las ausencias, y enfermedades en cuyo caso esta prompto ha havilitarse y exponerse de Boticario por el Real Protomedicato»9.

Esta petición se realiza en 1758. Ello nos indica dos cosas; en primer lugar, las ausencias ocasionales, sin prolongación en el tiempo, eran suplidas por el oficial; ahora bien, al producirse éstas de forma reiterada, o por espacios prolongados de tiempo, se precisaba de un boticario examinado que asumiera en plenitud las responsabilidades de la oficina; es por ello, por lo que el mancebo Cuervo se ofrece a obtener el título de boticario, siendo además tal requisito imprescindible para en su día ocupar el cargo que pretende.

El oficial o mancebo tenía un destacado papel en los inventarios que se realizaban al fallecimiento de un boticario. Tales recuentos determinaban las responsabilidades materiales exigibles a los herederos del titular fallecido, una vez contabilizado el balance de los géneros y utensilios de la botica y justamente, en su realización, tenía opinión cualificada el auxiliar como persona conocedora de las cosas de la oficina. En cualquier circunstancia el oficial en tareas de regencia contraía, además de las propias responsabilidades en el aspecto técnico, las contables, derivadas del control de los géneros que entraban o salían de la botica. El propio J. F. Ramos aparece nuevamente en esta tesitura: el 26 de noviembre de 1729 firma la solicitud de los géneros que son precisos para la botica, a fin de que sean adquiridos por la Administración del Centro ${ }^{10}$. Casi un año después el mismo oficial se hace receptor de otros géneros solicitados para la oficina por el boticario titular ${ }^{11}$.

En Octubre de 1797 tiene lugar un episodio sumamente ilustrativo del organigrama de la botica. El oficial Francisco Xavier Areán solicita permiso para desplazarse a Madrid con el objeto de cursar estudios de medicina. A la vista de ello, la Real Cámara recaba información al respecto al Administrador del Hospital ${ }^{12}$ :

«En la Cámara se ha vuelto a ver el recurso de $\mathrm{Fc}^{\circ}$ Xavier Areán, Boticario segundo del Hopl...en solicitud se le concediese licencia por un año para poder venir a Madrid a oir lecciones de Medicina practica, sin cuyo requisito no podía recibirse de Médico...con el goce del sueldo que disfruta como segundo boticario,... aunque fuera dexando un sustituto. La Cámara ha venido en conceder la licencia...con la precisa condición de que deje un sustituto hábil y capaz y que desempeñe el empleo de segundo boticario a satisfacción del primero...»

Manuel García Cuervo, primer boticario, acepta la resolución de la Real Cámara. Por su parte Areán designa para sustituirle al mancebo primero de los de la botica de D. Julián Suárez Freire, farmacéutico de Santiago y Visitador General de Boticas del Reino. Este nombramiento y actitud de Areán no debieron ser del agrado de Manuel

\footnotetext{
9 AHRC. Cédulas Reales, 510

10 AHRC. Cuentas, $459 / 1$

11 AHRC. Cuentas, 71.

12 AHRC. General, 764.
} 


\section{J. SANTIAGO SANMARTÍN MIGUEZ}

García Cuervo que, en escrito al Administrador, dice que Areán se intitula indebidamente, «Boticario Segundo de esta Real Casa». Ante esta audacia, el farmacéutico invoca las Constituciones 47 y 70 de las de 1524 , la $1^{\text {a }}$ de 1590 , y el mandato 29 de los de 1697, que hacen relación a él como único boticario del Hospital y, por tanto, encargado de la oficina, de sus géneros y utensilios, siendo Areán oficial o mancebo, nunca segundo boticario. La Real Cámara, en atención a las alegaciones de una y otra parte opta en esta ocasión por un profesional experimentado para cubrir la plaza de oficial, desoyendo la recomendación del boticario, que por deducción proponía a un profano al que debería formar en el oficio. Como manifiesta la Real Cámara, el informe de la administración no fue favorable a los deseos de Manuel Cuervo, debiendo ver la marcada hostilidad del boticario hacia el oficial, que evidentemente restaba objetividad a sus consideraciones respecto al mejor servicio de la farmacia.

\section{LA FORMACIÓN DE LOS BOTICARIOS DEL HOSPITAL}

La formación técnica de los boticarios del Hospital es uno de los aspectos que más interesa considerar a fin de valorar el nivel terapéutico que podía ofrecer la oficina que regentaban en relación con el conjunto de sus colegas españoles y europeos. Así como las fuentes en que bebieron los conocimientos en torno al medicamento fue variando a medida que lo hacía la consecución de nuevos conocimientos, el modo de acceso a las innovaciones técnicas sufrió pocas variaciones a lo largo del período estudiado. Pasamos a continuación a informar de la casuística que referida a la formación de los boticarios de la Obra Pía nos ofrece la documentación disponible.

La información de limpieza de sangre de Antonio Ramos de Solís, titular desde 1700, aporta alguna noticia relativa a su formación ${ }^{13}$. La declaración del escribano Antonio Moreno, de la jurisdicción de Sobrado, dice del Boticario:

\footnotetext{
«...luego que tuvo algún entendimiento, dichos sus padres le pusieron al exercicio de boticario con el padre frai Thomas González, boticario, monxe profesor en el Real Monasterio de Sobrado...donde asistió algunos años; de allí se pasó a bivir a la ciudad de Orense, donde también le ha visto y tratado asistiendo al mesmo exrcicio con un boticario de dicha ciudad y al mismo tiempo supo estudiaba Gramática y desde allí se paso según noticias a la Villa de Madrid donde tiene por cierto se examinó de boticario...»
}

Ya mediada la centuria, Juan García Cuervo pasó a servir en la botica en calidad de oficial. Por lo que manifiesta más tarde, había ya realizado un aprendizaje en la oficina de un farmacéutico aprobado, que le transmitió los rudimentos precisos para manejarse en la profesión. Para ser admitido para la plaza de mancebo, hacia el año

13 AHRC. General, 1.700. 
1738, fue evaluado por los médicos y cirujano de la Casa, que lo hallaron suficiente ${ }^{14}$. Esta prueba, desde luego, no tenía validez más que para establecer un criterio de contratación y no sobrepasaba el ámbito interno del Hospital. Veinte años después, el oficial Cuervo, en escrito dirigido a la Real Cámara en fecha 27 de Septiembre de 1758, solicita la provisión de la plaza de boticario en previsión de una probable vacante, dado el delicado estado de salud del titular. Debido a la carencia de titulación que le capacitara para el cargo, manifiesta «...esta prompto ha havilitarse y exponerse de Boticario por el Real Protomedicato. Así lo espera el splcte. a lo que sea mas del Rl. aquerdo de V. M.»

En el capítulo dedicado a los nombramientos de boticario describiremos detalladamente este episodio, por lo que no vamos aquí a insistir más. En cualquier caso, puede ser revelador de la poca oferta de boticarios en esa época el hecho que el solicitante, que a la postre será nombrado farmacéutico titular, no esté examinado y que supedite el trámite a la previa provisión de la plaza en su favor. Es el caso que unos años después de esa petición, en 1763, va a producirse la vacante de la plaza por fallecimiento del titular Agustín Valero. La competencia que se crea entre los dos aspirantes y la necesidad de presentar sus méritos ante la Cámara nos va a permitir conocer la secuencia formativa de ambos. Miguel Valero, hijo del difunto farmacéutico, estuvo de muchacho en la botica del Hospital, practicando con su padre en calidad de aprendiz; pasó después a ejercer como oficial a la del Colegio de la Compañía de Monforte de Lemos, donde permaneció algunos años, estableciéndose posteriormente en la ciudad de León ${ }^{15}$.

Juan García Cuervo, por su parte, antes de entrar a servir la plaza de tal oficial mayor, practicó por espacio de más de cuatro años en la farmacia del Monasterio de Cornellana con Fray Mauro Fernández, su boticario. Posteriormente, al entrar en el Real Hospital practicó con Agustín Valero durante veinticuatro años, sustituyéndolo con frecuencia, haciéndolo en el momento de la solicitud por vacante de aquél ${ }^{16}$.

En alguna ocasión, la formación del boticario sobrepasaba la que la ley le exigía para ejercer la profesión. Son varios los ejemplos que de ello encontramos en la casuística de los farmacéuticos del Hospital. En algunos casos, los que ejercen en ella tienen la titulación de Doctor en Farmacia - si bien ello ocurrirá en un período posterior al que ahora nos ocupa-, pero también se da la circunstancia de adjuntar a su titulación otras afines, como la de cirujano o médico. Es variable el orden en que adquieren estos dos últimos grados y el de farmacéutico. Presentamos a continuación unos casos que avalan esta circunstancia.

14 AHRC. Cédulas Reales, 510.

15 AHRC. Cédulas Reales, 527.

16 AHRC. General, 53 / 1.720. 


\section{J. SANTIAGO SANMARTÍN MIGUEZ}

Antonio Ramos de Solís estuvo al frente de la botica entre los años 1700 y 1723 . Unía a su condición de farmacéutico la de médico. Solicitó la baja como boticario para pasar a engrosar la nómina de médicos del propio Hospital.

Francisco Javier Areán, por su parte, actuó como oficial de la botica gozando ya del título de cirujano al tiempo que tenía el de farmacéutico. No contento con ello, en 1797 solicitó permiso para trasladarse a Madrid, con el fin de cursar asignaturas de medicina y obtener esta licenciatura, cosa que conseguiría, pasando a ocupar posteriormente plaza de médico en el Hospital.

\section{SUELDOS Y CONDICIONES DE VIDA DE LOS BOTICARIOS}

La economía personal de los funcionarios del Hospital no es un aspecto nimio en la investigación que nos ocupa, y es así por muy diversos motivos, que no por bien sabidos debemos soslayar. La retribución del farmacéutico nos va a dar una referencia bastante aproximada de la estimación profesional que éste gozaba dentro del organigrama del conjunto hospitalario, más aún: esta referencia servirá para situarle en el lugar del conjunto de la sociedad que ocupa a lo largo de los cien años que estudiamos. Para ello serán precisas al menos dos coordenadas: por un lado confrontar sus emolumentos con los de otros profesionales del mismo Centro y, por otra parte evaluar las posibilidades que esas retribuciones ofrecían a ese personal en el ámbito del día a día que se sucede en cada momento considerado. Afortunadamente, aunque con desigual distribución, disponemos de abundante documentación para ilustrar el capítulo de las retribuciones.

Era una práctica frecuente en los años que estamos considerando y, más aún tratándose de un establecimiento de régimen de vida comunitario, que los salarios se compusieran de dos conceptos. En primer lugar el empleado percibía la parte más jugosa del sueldo en dinero líquido; sin embargo, había otra porción del mismo nada desdeñable que se le entregaba en especies: tal concepto recibe el nombre de ración. Junto con estas dos aportaciones el boticario disfrutaba de una vivienda en las propias dependencias del Hospital, en las que residía él y su familia. Esta vivienda, al igual que las de otros empleados de la Casa, cambió de ubicación con el transcurso de los años, situándose en el siglo XVIII en unas casas que el Hospital tenía junto a la fachada occidental del edificio principal, en lo que hoy en día es la calle de Carretas y con acceso directo a las dependencias sanitarias.

La obligatoriedad de vivir en el recinto hospitalario constituía para el boticario, sin duda, una servidumbre irrenunciable, pero suponía al mismo tiempo una notable retribución por ahorro de vivienda que completaba un sueldo que, de carecer de este capítulo hubiera sido, sino escaso tampoco holgado. Para hacernos una idea de lo que en metálico suponía la vivienda vamos a referirnos a unos datos del siglo XVIII ofre- 
cidos por el profesor de la Universidad de Santiago Dubert García ${ }^{17}$. El coste de la vivienda variaba enormemente con la situación de la misma. Las clases sociales más pudientes habitaban el centro de la ciudad, es decir la zona de intramuros, siendo la periferia la zona a la que en mayor lugar quedaba relegada la población humilde, de escasos recursos. Respecto a los precios, veamos el siguiente cuadro que nos da una idea muy general y tal vez cabría decir que extrema, estando sujeta numerosas variaciones particulares:

\begin{tabular}{|l|c|c|}
\cline { 2 - 3 } \multicolumn{1}{c|}{} & Intramuros & Extramuros \\
\hline Arriendo anual & 1.243 .13 rs. de vellón & 288.93 rs. de vellón \\
\hline
\end{tabular}

Teniendo en cuenta que la vivienda del farmacéutico estaba situada justamente por donde en su momento discurría la muralla, aunque eso sí, sumamente céntrica, cabría darle una valoración intermedia entre las más baratas y las viviendas denominadas céntricas. El propio Hospital era poseedor de no pocos bienes inmuebles de los que obtenía jugosas rentas mediante su arriendo. Por citar un ejemplo de 1740, una casa situada en la vecina calle de San Francisco, menor desde luego que la ocupada por el boticario, pagaba un arriendo anual de 390 reales $^{18}$. No son sin embargo las de esta zona las casas más cotizadas de las de intramuros —éstas se situarían en las calles paralelas que conducen a la catedral, denominadas rua Nueva y rua del Villar-, por lo que mediante un ajuste razonable, a la del boticario cabría darle una valoración de arriendo cercana a los 500 rs. de vellón anuales.

La vivienda que el Hospital ponía a disposición del personal de la farmacia afectaba tan sólo a su titular y no era extensible al resto de sus empleados; no obstante, se dan circunstancias puntuales que aconsejan la concesión de este favor a los mancebos. Ya hemos indicado que la vida del Hospital estaba concebida como una extrapolación laica de la vida cenobítica y así se esforzaron en expresarlo las sucesivas Constituciones. En este marco se sitúa la necesidad de ofrecer a una serie de Ministros una vivienda que, aunque dotada de posibilidades de intimidad, cobijaba en el mismo recinto y acercaba física y vivencialmente a sus miembros más destacados. Más adelante nos ocuparemos con detalle de los llamados «aposentos del boticario». Vamos ya a considerar ahora los salarios de los profesionales de la botica en el período en el que se inscribe nuestro estudio.

Ignacio Arredondo y Recamán, que ejerció como titular desde 1723 hasta 1731, percibía una retribución de $40.000 \mathrm{mrs} .{ }^{19}$ que equivalen a unos 1.249 reales si tene-

17 Dubert GARCía, I. (1987), Los Comportamientos de la familia urbana en la Galicia del Antiguo Régimen. El ejemplo de Santiago de Compostela en el siglo XVIII, Santiago de Compostela, p. 114 y s.s.

18 AHRC. Cabildos, Juntas, 15.

19 Ibidem, 55-57-59. 


\section{J. SANTIAGO SANMARTÍN MIGUEZ}

mos en cuenta el ajuste monetario llevado a cabo por los Reyes Católicos. En 1728, el regente de la botica del Hospital de Gracia de Zaragoza cobraba 500 reales de plata anuales, es decir 44.500 mrs., aumentándose al doble en 1750. Además de esta percepción en metálico hay que añadir la ración diaria, tanto para él como para su mujer, de «12 onzas de carnero y otras 12 onzas de tocino para ambos, 4 onzas de garbanzos o 6 de judías, 4 libras de vino, 4 libras de pan y algo de verdura ${ }^{20}$. En el año 1741 se detallan los salarios de todos los Ministros Mayores ${ }^{21}$ :

Médicos: 70.000 mrs. anuales. No tienen ración alguna.

Cirujano: 60.000 mrs. anuales. No tiene ración.

Boticario: 40.000 mrs. anuales. Tiene ración, similar a la que se describe más adelante.

El Catastro de Ensenada de 1752 nos proporciona información del número de boticarios establecidos en Santiago y la estimación de sus rentas 22 :

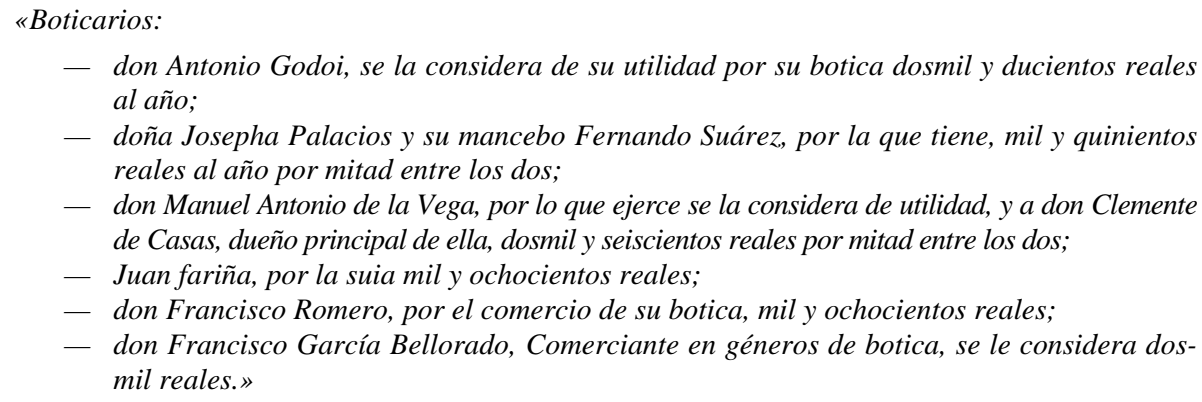

- don Antonio Godoi, se la considera de su utilidad por su botica dosmil y ducientos reales al año;

- doña Josepha Palacios y su mancebo Fernando Suárez, por la que tiene, mil y quinientos reales al año por mitad entre los dos;

- don Manuel Antonio de la Vega, por lo que ejerce se la considera de utilidad, y a don Clemente de Casas, dueño principal de ella, dosmil y seiscientos reales por mitad entre los dos;

- Juan fariña, por la suia mil y ochocientos reales;

- don Francisco Romero, por el comercio de su botica, mil y ochocientos reales;

- don Francisco García Bellorado, Comerciante en géneros de botica, se le considera dosmil reales.»

Como vemos, en ese momento el sueldo del boticario del Hospital estaba muy por debajo de las ganancias que proporcionaba el ejercicio libre del farmacéutico establecido, incluso considerando el caso de Fernando Suárez, que no siendo propietario de oficina, debía actuar como regente de la de Josefa Palacios, con un sueldo que doblaba al del Hospital. Esta desventajosa situación se vio corregida con el incremento de los salarios que tiene lugar poco después, ya que aunque Agustín Valero comenzó percibiendo el mismo sueldo que su antecesor, durante su ejercicio, veinticinco años más tarde, se emite una Real Cédula por la que se concede al boticario un aumento de salario sobre el sueldo y ración que hasta aquí gozaba, con ochocientos reales de

20 ANDRÉS ARRIBAS, I., (1992), La Botica del Hospital Real y General de Nuestra Señora de Gracia de Zaragoza (1425-1808), Madrid, p. 63.

21 Hay que tener en cuenta a la hora de evaluar las cifras económicas manejadas de aquí en adelante, que Felipe V fijó en 1737 el valor del Real en 68 Maravedís.

22 EIRAS Roel, A. (1990), Santiago de Compostela 1752. Según las Respuestas Generales del Catastro de Ensenada, Madrid, p. 101. 
vellón al año desde 26 inclusive del mes de Enero de 1756 en adelante. La Ración permanece inalterable y se trata de los siguientes productos:

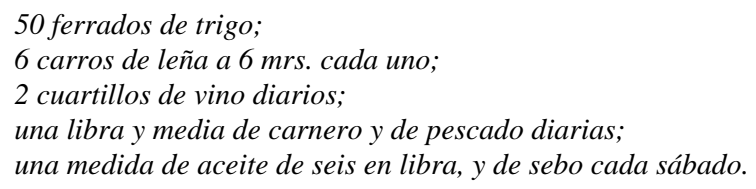

Esta ración se cifra, en el propio documento, en un valor monetario de 10.189 mrs. anuales, cuya equivalencia en reales sería de unos 149 aproximadamente. El aumento de salarios de 1756 no afecta únicamente a la botica, sino que se incluye en un ajuste salarial que afecta al conjunto del personal empleado en el Hospital ${ }^{23}{ }$.

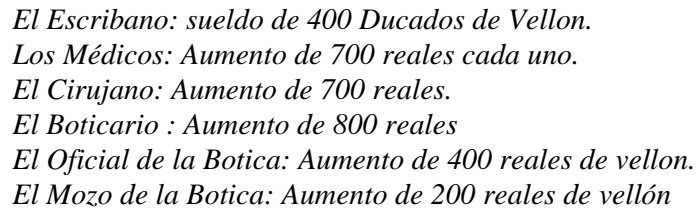

Estos aumentos son anuales. La Real Cédula es de 22 de Febrero de 1756 y, por lo que se desprende de la petición de los interesados, el incremento de los salarios era ya una vieja aspiración de los mismos: el documento del Rey Carlos III alude a que la petición se había hecho ya a su padre Don Fernando VI, que había fallecido tres años antes. Ciertamente el desfase de honorarios debía ser considerable; tengamos en cuenta que en lo que respecta al boticario la última adaptación del sueldo a las necesidades reales del momento se remonta a 1594, año en que a Pedro Curiel se le concede un aumento de 10.000 mrs. con respecto a los 30.000 que percibía hasta entonces. Han tenido que pasar nada menos que 162 años para revisar nuevamente los salarios.

Sin embargo, comparando estos emolumentos con los que se pagan en otras instituciones hospitalarias no los podemos considerar escasos. Continuando con los datos que disponemos del Hospital de San Hermenegildo y el del Amor de Dios de Sevilla para el siglo XVIII (no se incrementaron hasta 1789), percibía el boticario alrededor de 35.000 mrs., además de la vivienda y la ración correspondiente, a lo que habría que añadir una ayuda de costa que se sitúa en 44 reales anuales $(3.916 \mathrm{mrs})^{24}$.

No pudo gozar el Boticario muchos años de su revaluada retribución ya que falleció repentinamente en Noviembre de 1762. Debido a esta circunstancia, se confirma la continuidad de Juan García Cuervo, a la sazón oficial de botica, como farmacéuti-

\footnotetext{
23 AHRC. Reales Cédulas, 504.

24 HERRERA DÁviLA, (1990), p. 337.
} 


\section{J. SANTIAGO SANMARTÍN MIGUEZ}

co interino desde el fallecimiento del titular Agustín Valero en tanto no se nombraba sustituto. Cuervo ocupa la plaza de oficial desde 20 de Noviembre de 1758. Se fija como condición,

«...que no haya de gozar, ni goze mas ración ni sueldo, que el que le está consiganado por tal oficial Mayor de Botica, esperando de S.M. la recompensa dignandose de tener presente su mérito para la provisión de dicha plaza...».

Vemos que se le otorga un aumento de responsabilidad que no va acompañado de un incremento en su retribución, eso sí, a la espera del nombramiento como titular, que compensaría sobradamente la relativa penuria de este período interino. Efectivamente, el 30 de Junio de 1763 Juan García Cuervo toma posesión de la plaza de boticario en propiedad. Tras veintidós años al frente de la farmacia falleció el 30 de Octubre de 1785 en su vivienda, dentro del Hospital, siendo enterrado en la Iglesia del Establecimiento. Al día siguiente de su deceso se realiza un completo inventario de sus bienes, del cual se da valoración y a petición de Manuel Cuervo, su hijo, se hace almoneda judicial de los bienes fincables del finado (venta pública en subasta), sumando un total de 4.080 reales y 28.000 maravedís, que se distribuyeron entre el propio Manuel y su yerno Juan de Mella. Por constituir la vivienda parte de los emolumentos del farmacéutico y por ilustrar de forma singular el modus vivendi en materia tan personal como es su casa y sus enseres, reproducimos a continuación el contenido del inventario que en relación a la vivienda de un boticario del siglo XVIII podemos considerar excepcional por lo minucioso de su descripción ${ }^{25}$ :

$1^{o}$ quarto que dice a la guerta

Se hallaron en el tres taburetes de mos cobia viexos y sin quasi servicio Iden un banquito pequeño de madera de castaño usado

Dos gorros de hilo hordinarios para la caveza

una sabana de estopilla de dos lienzos y medio viexa

\section{$2^{\circ}$ quarto}

Un escaparate sobredorado con sus tres vidrios finos viexo una Alazena de madera de castaño con pechadura y llabe viexo y dentro della (alimentos y ropa) Un taburete cubierto de moscobia viexo

Un catre de madera de castaño tambien viexo

Un baul de pino ahorrado de taparata y cubierto de cuero, y dentro deel: un bestido de paño compuesto de casaca, chupa y calzon color de texa con botonadura de plata y forro azul bien tratado. Un par de medias de lana felpadas color aplomado viexas.

Una mesa de manteles echura de busanillo nueva.

Un gorro de hilo para la cabeza sencillo.

Un brasero con su copa de cobre usado.

\footnotetext{
25 AHRC. General, 1.080.
} 


\section{LOS BOTICARIOS DEL HOSPITAL REAL DE SANTIAGO DE COMPOSTELA EN EL SIGLO XVIII}

\section{$3^{o}$ quarto}

Un catre tambien de madera con su lona viexo.

Un jergon de estopa lleno de paxa maiz viexo.

Otro catre tambien de madera de castaño valaustrado usado.

Dos colchones de texlis con lana de Castilla usados.

Un bufete de madera de castaño de cuatro pies usado.

Otro pequeño redondo madera de pino.

Otro tambien pequeño usado.

Un escaparate dorado con sus tres bidrios y la Imagen de Nuestra Sra. de los Dolores.

Quatro cortinas y cielo de un catre de lienzo pintado.

Un Argadillo y un Sarillo de palo.

Un calzon de sarga de nimes negro viexo.

Un sobre tude Baieton color aplomado viexo.

Una casaca y chupa de paño color de pasa viexo.

Tres chupas viexas sin mangas.

Una casaca y chupa de limistre negro viexo.

Un bufetico madera viexo.

Una campanilla de metal.

Dos quadros con los marcos de madera con la Imagen de San Antonio y otra de Ntra. Sra. de Velen.

\section{$4^{\circ}$ quarto}

Seis silletas de paja pequeñas, i otras seis grandes pintadas.

Ocho cortinas de ventanas de lienzo pintado y quatro zenefas de madera pintadas.

Un quadro de la Madalena con su marco dorado.

Otro de San Pedro con su marco.

Otro de la Santisima Trinidad con su marco.

Otro de la Virgen de los Dolores.

Otro de la virgen de Nieba.

La imagen de San Juan Nepomuseno con sus medias cañas.

Otra de San Francisco Xavier con dhas medias cañas.

Optro de Santa Escolastica con su marco de madera. Cinco Jicaras de media china.

Siete platillos de lo mismo.

Una cafetera de cafe.

Un friso de enserado para la sala usado.

\section{$5^{\circ}$ quarto}

Dos taburetes de madera de Castaño viexos: otro de moscobia tambien viexo.

Un bufetico de madera usado.

Una mesa de manteles de Busanillo, y seis servilletas de lo mismo.

\section{$6^{\circ}$ quarto}

Un belon de metal viexo.

Un Arca de madera de Zedro con pechadura y llabe. (contiene ropa).

Un bufete redondo madera de castaño viexo. 


\section{J. SANTIAGO SANMARTÍN MIGUEZ}

\section{Cozina}

Una palangana, doze platos, una fuente y media fuente de estaño usados. Quatro cazos de Aramio concavos de fierro viexos.

Quatro sartenes viexas de lo mismo.

Dos candeleros de metal usados y una espabiladera.

Un almirez de metal con su mano pequeño.

Dos espumaderas y una cuchara de fierro.

Una media luna con sus dos cabos de madera.

Dos azadones de fierro viexos.

Un baño viexo de madera de castaño.

Una Artesa de amasar pan viexa.

Seis escodillas de Talabera: seis cubiertos de palo y un cuchillo viexos.

Dos calderos de cobre pequeños con zintas y aros de fierro viexos.

Una caldera de palo de carretar agua viexa y una ferrada de cobre.

Una chocolatera de cobre con su molinillo de palo.

Un picadero de palo: una zernidera y quatro basos de bidrio y otras tantas jicaras de Talabera.

\section{Quartico de avaxo}

Un bufete de quatro pies madera de Castaño y sobre el una Papelerita de palo pequeña con varios caxones pechadura y llabe y dentro de ella se halló lo siguiente:

Dinero.

Una capa de paño usada color ablancasada con banda de felpa de color.

Una muestra: un espadí con su puño, una caxa, trs cucharas de plata, dos grandes y otra pequeña con un tenedor de lo mismo.

Un juego de hibillas de plata iotra de corbati tambien de plata.

Un taburete de madera.

Un Arcon de madera de pino (contiene maíz).

Una caña viexa de mano.

Una caxa de carton: otra de plata con su cubierta de venturina y una escobilla.

Una efixie de un Santissimo Christo de bronze pequeño en una cruz.

Una caxa de Alamo con dos peluquines y sin sombrero usado.

Unas Polainas de palo usadas.

\section{Quarto de Bodega}

Una quarterola de unos seis cañados de vino blanco, otra sin el: un Pipotico pequeño: cosa de quatro carros de leña.

Un zerdoso que valdrá unos doscientos reales.

\section{Quarto del criado.}

Un bufete de madera de Castaño de quatro pies: un banco de respaldo de la propia madera: un estante: dos taburetes: una tixera: un jergon de estopa viexo: una sabana tambien de estopa viexa: una manta de burel: un cobertor de lana de Castilla y una Almohada con lana.

En varios papeles, de los hallados durante el inventario, se especifica que el finado recibía rentas de unas propiedades que poseía en Santa Cristina de Campaña y Santa Columba de Louro. Al difunto boticario le sucede su hijo, y después su nieto; ambos fueron enterrados en la Capilla del Hospital. 
Ante la demanda reiterada de los médicos y cirujano, en el año 1792 el Administrador del Hospital propone un reajuste de salarios que posteriormente es aprobado: la Real Casa emite una Cédula por la que se incrementan los emolumentos, al tiempo que determinadas raciones se transforman en dinero efectivo. También hay un reajuste de las plazas de Ministros y Oficiales, que se harán efectivas a medida que los mismos vayan faltando ${ }^{26}$. Veamos los salarios que se determinan:

«MAYORDOMO: No tiene ración. 3.012 Rs. y 32 mrs.; se le aumentan 587 rs. y 2 mrs, lo que hace un total de 3.600 rs.

SECRETARIO: Ración entera de Ministro Mayor (valorada en 1.612 rs. y 26 mrs.). En dinero 3. 274 rs. y 20 mrs.; más 550 rs. como Comisario de Entradas. Total: 5.537 rs. y 12 mrs. aumento 175 rs. y 14 mrs. Quedará con un total de 5.712 rs. y 26 mrs.

MÉdICOS: Sin ración, esta se transforma en 126 rs. y 6 mrs. en concepto de almuerzo. En dinero, 3.300 rs.. Aumento: 1.420 rs. y 20 mrs. Quedará un total de 4.846 rs. y 26 mrs. anuales, para cada médico.

CIRUJANO: Sin ración. Sueldo : 2.802 rs. y 12 mrs. mas 126 rs. y 6 mrs. de almuerzos. Aumento: 197 rs. y 22 mrs en dinero. Total 3.000 rs. mas ración.

BOTICARIO: Tiene ración entera de Ministro Mayor, que consta de 50 ferrados de trigo, 6 carros de leña, 2 cuartillos de vino y libra y media de carne cada día, además de 10 extraordinarias cada año, de ambas especies, 2 cuartillos de aceite, y dos libras de velas (peso Castellano) al mes. Todo ello tasado en 1.612 rs. y 26 mrs., más almuerzos (126 rs. y 6 mrs.), en dinero: 1.976 rs. y 16 mrs. Hace un total de 3.815 rs. y 14 mrs. Aumento de Sueldo: 423 rs. y 18 mrs., además del aumento en ración. Queda un total de 2.400 rs. además de la ración. El total de lo percibido en esta plaza será de 4.160 rs. y 26 mrs. Hay que añadir el disfrute de la vivienda.

OFICIAL DE BOTICA: Goza de un salario anual de 1.000 rs, teniendo además asignada una ración de una libra de carne diaria y alguna extraordinaria, por valor de $580 . .32$ rs. anuales y 72 rs. en concepto de leña.»

Comparativamente, en esas mismas fechas — concretamente en 1789-el salario del boticario del Hospital de San Hermenegildo de Sevilla era de 540 reales (imaginamos que se trata de la moneda de plata ${ }^{27}$. Folch Jou ofrece para el período comprendido entre 1749 y 1800 una estimación del beneficio que como promedio obtiene un boticario establecido: esta cantidad la sitúa en torno a los 2.900 reales de vellón ${ }^{28}$. De estos datos deducimos que, tras la actualización de salarios llevada a cabo en 1756, el nivel de ingresos de los boticarios del Hospital compostelano podía considerarse elevado en comparación al del promedio que en todo el Reino percibían sus colegas.

\footnotetext{
26 AHRC. Cédulas Reales, 613.

27 HERRERA DÁVILA, (1990), p. 347.

28 FolCh Jou, G. y otros, (1986), Historia General de la Farmacia, El Medicamento a través del tiempo, Madrid, vol. 2, p. 482.
} 


\section{PROCEDENCIA Y EXTRACCIÓN SOCIAL}

No son muchos los datos, de los que la archivística nos ha legado, que incidan en aspectos personales de los profesionales de la Botica. Hubiera resultado interesante acercarnos al perfil humano de los boticarios a lo largo de los años. Saber de sus costumbres, sus aspiraciones, etc. También sería interesante conocer sus criterios y actividades al margen de la labor profesional, su «ideología». No quisiéramos dejar de lado sus orígenes, su extracción social y económica. Nos importa igualmente su lugar de procedencia, su adaptación a la ciudad donde ejercen, y sus relaciones con otros conciudadanos. Sólo en parte podremos abordar estos aspectos, al menos, con los datos que la archivística del Hospital nos ofrece; ello será siempre a través de someras informaciones traídas a colación como complementarias de asuntos más puntuales y referidos a su actividad profesional.

El boticario, desde el momento en que su profesión se diferencia de otras con las que había convivido largamente - cereros, especieros, etc.—, va adquiriendo un prestigio creciente. Si en un principio se le sigue considerando un artesano específico, con el tiempo, su arte se tiñe de consideración científica. Recordemos que a partir de 1650, la Farmacia, a diferencia de otros artes y oficios, pasa a ser considerada Arte Científica, siendo tal reconocimiento socialmente aceptado, dotando además a sus practicantes de algunos privilegios y mayor relevancia ${ }^{29}$. La reglamentación y exigencias para la obtención del título de Boticario, amén de aumentar su formación, le conferirán un prestigio que, con las normales excepciones, acrecentará con su cotidiano quehacer. No faltarán, no obstante, voces malintencionadas que se encargarán de recordarle su origen meramente manual y comercial.

Un estudio realizado por Eiras Roel en $1984^{30}$ nos acerca al conocimiento de las élites urbanas de Santiago de Compostela a mediados del siglo XVIII, que nos será de gran utilidad para referenciar a nuestros protagonistas. En primer lugar, nos presenta un cuadro de distribución de la profesión por estamentos:

\begin{tabular}{|l|c|c|}
\hline & Vecinos & $\%$ \\
\hline Vecinos ciudad de Santiago 1752 & 4.504 & 100,0 \\
\hline Elites urbanas & 155 & 3,4 \\
\hline Clases medias urbanas & 583 & 12,9 \\
\hline Artesanado urbano & 1.798 & 39,9 \\
\hline Indeferenciados, pobres y campesinado & 1.968 & 43,7 \\
\hline
\end{tabular}

29 Lafuente, A., Puerto, J. y Calleja, M C C., (1988), Ciencia y sociedad en España. Madrid.

30 EIRAs Roel, A. (1982), «La Documentación Notarial y la Historia». Actas del II Coloquio de Metodología Histórica Aplicada. 2 vol. Vol. I, Santiago de Compostela, p. 117 y s.s. 
El autor del trabajo se plantea la complejidad de criterios — sin duda cambiantes- para la determinación de la élite y, en consecuencia, también será dificultosa la adscripción de los individuos a las clases con ella colindantes. Tres son los parámetros que tradicionalmente parecen encuadrar a los individuos en una determinada clase: la fortuna, el linaje y el poder. Sin embargo, en el período histórico que estamos considerando, estas tres circunstancias parecen no tener una validez definitiva, ni siquiera el uso o carencia del don en el tratamiento. Citamos los ejemplos aportados por Eiras Roel. Pese a su probable linaje hidalgo, nadie en 1752 tendría por miembros de la élite a D. ${ }^{a}$ Gabriela de Andrade, palillera (...) y sus hermanas (...) reconocidas como Doñas en los padrones catastrales; ni a Don Antonio Pardo Maldonado, <<hidalgo pobre〉>; (...) ni a Don Juan Vicente Pardo, hidalgo notorio y Notario de profesión, (...) sin servidumbre alguna, al que se atribuyen unos ingresos catastrales (150 rs.) inferiores a los de los artesanos, ni siquiera a Don Manuel Basualdo, hidalgo y mercader de libros, típico representante de una clase media desahogada, soltero y con dos criadas, con unos buenos ingresos fiscales de 5.000 rs., pero menos que algunos alquiladores de mulas. En cambio si cabe considerar en la élite a algunos individuos de origen plebeyo, como el mercader y cambista de letras Don Manuel Antonio de Lago y Ben, hijo y hermano de campesinos sin don, prestamista aventajado, que reúne la condición de Tesorero de los Estados de Altamira y de la Cofradía de Clérigos de la Concepción.

Si la condición de hidalguía o de linaje no es condición suficiente para ser admitido en una determinada clase social, tampoco lo es la fortuna por sí sola, si no va acompañada de otras cualidades. Respecto al honor del don, es imprescindible para pertenecer a la clase más considerada, aunque no suficiente. Este tratamiento, extendido en esta época más que en las precedentes, sobre todo en la documentación notarial, esta restringido en la Catastral, «...(todos los escribanos, procuradores y notarios sueltos emplean el don en la documentación notarial, pero a casi ninguno se lo reconoce el Catastro, mientras que sí se lo concede a todos los abogados, médicos y boticarios, no así a los cirujanos ${ }^{31}$. Sin embargo, este tratamiento es poco significativo de la relevancia social de quienes lo ostentan. Eiras Roel añade unos ejemplos que nos interesan. Cita a Don Diego de Ponte, abogado de poca clientela, que tiene unos ingresos fiscales estimados en 330 rs., que contrastan con los 7.700 de su colega Don Juan Ramírez o Manuel Montero, médico suelto, con 1.100 rs., frente a los 12.000 del médico del Cabildo don Plácido del Villar. Se menciona también al Boticario «...Antonio Godoy, a la altura de los restantes boticarios por cuanto a la utilidad de su botica...» que se estima en 2.200 rs.. Por último se cita el ejemplo de dos cirujanos con unos ingresos de 2.200 y 1.100 rs., respectivamente. Todas estas cifras habría

\footnotetext{
31 Ibidem.
} 
que tomarlas con cierta prevención por cuanto se tratan de ingresos fiscales estimados, y no exactamente de retribuciones reales.

Continuando con el trabajo que venimos citando, transcribimos a continuación, en las partes que interesan a nuestro estudio, un cuadro de distribución relativo a la condición social de una serie de profesionales, elaborado con datos de la sociedad compostelana a mediados del siglo XVIII:

\begin{tabular}{|l|r|c|c|}
\cline { 2 - 4 } \multicolumn{1}{c|}{} & Grupo & Elite & C/ medias \\
\hline Caballeros, hidalgos y viudas & 123 & 43 & 80 \\
\hline Deán y canónigos & 41 & 41 & - \\
\hline Presbíteros, Capellanes & 199 & - & 199 \\
\hline Abogados & 18 & 2 & 16 \\
\hline Notarios legos & 100 & - & 100 \\
\hline Médicos & 7 & 1 & 6 \\
\hline Boticarios & 7 & 1 & 6 \\
\hline Cirujanos & 12 & - & 12 \\
\hline Mercaderes & 65 & 11 & 54 \\
\hline
\end{tabular}

Con estos datos podemos intentar una aproximación al estatus social del boticario del Hospital. En principio, parece que en esta lista de profesionales superiores el boticario civil estaría porcentualmente por encima de la media, únicamente superado por Caballeros, Deán y Cabildo y Mercaderes. Estaría igualado con los Médicos y por encima de Cirujanos, Notarios, Presbíteros y Capellanes. Respecto a la situación del farmacéutico del Hospital, hay que considerar en un principio el sueldo. Tras el incremento en 800 rs. que se produce en 1756, su retribución queda establecida en unos 1.250 rs. anuales, a los que habría que sumar el valor de la ración y el de la vivienda. La ración permaneció inalterable durante muchísimas décadas, tal como se ha visto en su capítulo; en el momento que estamos considerando, es decir hacia la mitad del siglo XVIII, su valor se estimaba en 114 rs. de vellón. Por su parte, la vivienda tiene unos precios de más difícil valoración, pero también veíamos que los de las viviendas situadas dentro del antiguo recinto amurallado de la ciudad no debían bajar de los 500 rs. de vellón por el alquiler anual. Teniendo en cuenta las tres partidas que constituyen la retribución del boticario, es decir, sueldo, ración y vivienda, obtenemos un montante de aproximadamente 1.864 rs. de vellón anuales. Esta cifra le sitúa a un nivel parejo al de los boticarios civiles —algo por debajo— de la misma ciudad de Santiago.

Veremos en otro apartado la tirantez que boticarios y médicos mantenían en sus relaciones. Económicamente, lo vemos aquí, los médicos están muy por encima de los farmacéuticos en sus retribuciones. 
Una fuente copiosa de información acerca del origen de los profesionales de la botica del Hospital santiagués nos la proporcionan los expedientes de información de limpieza de sangre que se practicaban a los aspirantes, como condición imprescindible para poder acceder al cargo, que perduró hasta bien entrado el siglo XIX. Ya en las Constituciones de 1524, primeras que aluden directamente al Boticario, se prescribe la necesidad de ello. Recordemos la número 47:

\footnotetext{
«ITEN mandamos que aya en el dicho nuestro Hospital un Boticario Christiano limpio esperto, y de informacion dello examinado, ...» .
}

El procedimiento empleado en la obtención de la información de limpieza de sangre de los candidatos a la plaza de farmacéutico se repite en cada caso. Realizado el nombramiento del futuro titular, se comisionaba a un Oficial de la Casa para que se desplazara al lugar de origen de aquel. Una vez allí, el comisionado citaba a un número suficiente de personas conocedoras de la familia del boticario, a la que realizaba las reglamentarias preguntas ${ }^{32}$. No son escasos los expedientes de limpieza que la documentación conservada del Hospital nos ha legado. En todos, invariablemente, las respuestas obtenidas y por lo tanto la certificación expedida ha sido favorable al investigado.

A la muerte de su predecesor se procede al nombramiento como titular de Antonio Ramos, yerno del difunto, en su sustitución ${ }^{33}$. El Inquisidor del Reino y Administrador del Hospital D. Juan de Monroy, en cumplimiento de la legislación vigente, encomienda al botiller Pedro Suárez de Linares la información de Limpieza de Sangre del boticario electo. Al efecto de enfocar la investigación, el candidato presenta memorial de su genealogía. Dice ser hijo legítimo de Domingo Ramos y de María Solís, ambos vecinos de la parroquia de San Pedro de Porta, municipio de Sobrado (La Coruña).

A Antonio Ramos le sucede al frente de la botica Ignacio Arredondo y Recamán en 1723. Como a los anteriores, también al recién nombrado se le instruirá expediente de información. En este caso el Administrador, D. Francisco Ignacio de Aranceaga encarga los trabajos averiguatorios al Proveedor de la Casa, Jacobo Conde, que tras la acostumbrada recepción de genealogía se encamina a Pontevedra de donde eran vecinos los padres de Arredondo. Al día siguiente a su llegada, revisa con el párroco de San Bartolomé el libro de bautizados, en el que figura Ignacio de Arredondo y Recamán, bautizado el 23 de septiembre de 1693. Finalmente, Jacobo Conde, luego de interrogar a los testigos, certifica la limpieza de sangre de Arredondo el 5 de diciembre de 1723.

Agustín Valero, residente en la villa de Madrid, es nombrado boticario en sustitución de Ignacio Arredondo en $1731^{34}$. Oportunamente se ordena información de lim-

32 AHRC. General, 1.709.

33 AHRC. General, 1.700.

34 Ibidem. 
pieza de sangre; manifiesta ser natural de la villa de Nombela, diócesis de Toledo. Su padre D. Agustín Valero, que ha sido médico de esa villa, es oriundo de Villaroya de los Pinares, en Aragón. Su madre, María Ochoa, es natural de Sevilla. Su abuelo paterno, llamado también Agustín, procede de la localidad de Nobo en la provincia de Teruel. El agente comisionado para realizar la investigación se desplaza a Madrid, donde interroga a diez testigos. Como novedad, se toma declaración a su maestro boticario, de nombre José Guerrero, dueño de la botica que el pretendiente regenta en Madrid. En sus declaraciones le concede toda su confianza. El 29 de Mayo de ese año 1731 se redacta el informe de limpieza.

Como ya antes hemos comentado, los expedientes de limpieza de sangre son obligatorios para los candidatos a la botica del Hospital hasta mediado el siglo XIX. Sin embargo, la documentación conservada del Hospital Real no aporta más casuística que la hasta aquí reseñada, por lo que debemos acudir a otro tipo de expedientes con el objeto de conocer algo más sobre el origen y circunstancias personales de quienes trabajaron en ella.

Con motivo de un pleito en el que el oficial de botica Pedro Romero solicita acogerse a la jurisdicción del Hospital y que se comenta más ampliamente en el capítulo de los «Conflictos» ${ }^{35}$, sabemos que este oficial está vinculado estrechamente a la ciudad de Mondoñedo (Lugo), donde, se nos dice, poseía propiedades y allí marchará una vez cumpla su etapa como oficial de la farmacia del Hospital.

La familia García Cuervo, que aportó tres generaciones de boticarios al Hospital entre los siglos XVIII y XIX, ostentaba la condición de hidalguía, según certificación que se exhibe con motivo de la lectura del testamento de Manuel Cuervo. Tal certificación está fechada en Valladolid en el año 1796:

\footnotetext{
«...un libro cubierto de piel encarnada con guarniciones doradas y Broches de plata; y contiene una Real Provisión deestado de Ydalguia expedida por la Real chancilleria de Valladolid y sala de hijos dalgo deella con fecha de diez de Mayo del año mil ochocientos y al principio sellada con la nota de Registrada y las firmas del Dr. Don Bernardo Reoyo teniente de canciller mayor y Don Laureano Sanz y a lo ultimo otras tres diferentes...inserto un acuerdo deeste(ayuntamiento) su fecha diezyseis de Julio de mil ochocientos y uno ratificando el estado que habian dado a Don Manuel Cuerbo de hijo Dalgo en trece de Abril de mil setecientos y noventa y seis...». ${ }^{36}$
}

Aunque en medida menor a la deseada, hemos podido ofrecer en estas lineas algunas pinceladas relativas al origen de quienes, en cada etapa, dirigieron la oficina de la Institución. Como se ha visto, la procedencia geográfica corresponde mayoritariamente al ámbito gallego, siendo en cambio más diverso el origen social de los boticarios, aunque casi siempre ajustados a una franja social situada entre la clase burguesa

\footnotetext{
35 AHRC. Pleitos, 65.

36 AHRC. General, 1.095.
} 
- tanto de extracción rural como urbana- y la baja nobleza. Esta circunstancia se correlaciona con la casuística que, en lo relativo a esta profesión, se da en todo el territorio peninsular.

\section{NOMBRAMIENTOS}

Contemplaremos a continuación el criterio de elección de sus titulares, que es variable a lo largo de la dilatada existencia de la misma, y lo es lógicamente por cuanto diferentes son las condiciones que se dan en los profesionales y diferentes las necesidades de la farmacia en cada momento histórico. Frente a la dificultad de encontrar profesionales cualificados de los primeros tiempos, se produce una fuerte demanda a medida que nos acerquemos al siglo XIX, consecuencia de un mayor acceso a la formación profesional farmacéutica que se da en este período.

Recordamos que, como mandan las Constituciones, el nombramiento de Boticario - como Ministro Mayor que es- corresponde al Rey. Este nombramiento suele realizarse tras un informe de la Administración del Establecimiento, normalmente solicitado por el Real Consejo, que es el órgano ejecutor de los asuntos relacionados con el Hospital. Dicho informe es en sí mismo un pre-nombramiento, pues el Consejo suele corroborar lo informado por el Administrador. Los criterios que se siguen desde la propia Dirección de la Casa para aconsejar los nombramientos son muy variados, tal como comprobaremos al revisar la casuística que más adelante presentamos. En ocasiones se informa favorablemente de quienes ocupan la plaza de oficial mayor de la botica, mientras que otras veces parece importar más el parentesco con el anterior boticario. También puede influir en el nombramiento el conocimiento personal del aspirante, que se antepone a una contrastada competencia profesional. No faltan los casos denunciados de amiguismo o parentesco del elegido con el Administrador; hay que señalar que en el informe enviado por éste al Consejo, se citaban razones frecuentemente subjetivas que la Cámara rara vez se molestaba en contrastar, y ello a pesar de los ocasionales recursos que ante ella presentaban los candidatos rechazados. Más aún, cuando tal cosa sucede, es la propia Administración la encargada de recoger las opiniones de personas supuestamente imparciales que puedan aportar más luz en el contencioso.

El procedimiento que se utiliza para la selección de candidatos es asimismo variable. En algún momento se recurre al concurso público - tal método es regularmente utilizado en la última etapa de la historia de la botica, ya entrado el siglo XIX-, mientras que en el período que estamos considerando la pugna se lleva a cabo entre dos aspirantes vinculados anteriormente al Hospital. Ya no son solo los farmacéuticos desempleados los que concurren a la solicitud de la plaza, también farmacéuticos establecidos con botica propia pretenden un puesto que sin dudad era 


\section{J. SANTIAGO SANMARTÍN MIGUEZ}

apetitoso. Recordemos que con el paso del tiempo, el empleo de boticario de la Institución, en un principio no del todo bien remunerado, poco a poco ve adaptadas sus compensaciones económicas a las realidades en las que viven los farmacéuticos. Igualmente la revisión de salarios se hace más frecuente, pasando de estados monolíticos como los que se dan en los siglos XVI y XVII, a situaciones más razonables de los dos siglos posteriores.

Junto a los nombramientos, e íntimamente a ellos ligados, vamos a considerar las razones por las que se producen las vacantes. Aquí se va a dar también una casuística variable en función del momento histórico. Así, durante mucho tiempo, y con contadas excepciones, la causa más frecuente de vacante se produce por fallecimiento del titular. Era habitual en esta etapa que el boticario que accedía a la plaza no la abandonara en lo que le restaba de vida, convirtiéndose su persona en una institución, ya no solo en el ámbito del Hospital, sino en la ciudad de Santiago y su zona de influencia, que no era pequeña. De este modo, la plaza de farmacéutico del Hospital Real era apreciada no sólo por las ventajas y seguridad económica que pudiera reportar, sino también por el prestigio profesional y personal que confería a su poseedor.

Relativo al período que estamos considerando, el primer nombramiento documentado es el de Antonio Ramos de Solís:

«...Antonio Ramos de Solís a quien su magestad ha hecho merced de la plaza de Boticario de dicho Real Hospital por muerte de D. Juan López Carbajales para la que ha presentado Real Titulo en los veintisiete de enero próximo pasado deste año...sirva mandar se me acuda con la racion salario debidos de dicha plaza desde la muerte de Juan López boticario mi suegro en adelante en atencion de a verla servido desde entonces y estarla sirviendo actualmente... suplico a Su Señoria se me admita a la propiedad de dicho empleo y se me acuda con todo lo devido segun por dicho real título se previene.»37

El modelo de sustitución se repite con relación a los criterios del siglo anterior. Ramos, yerno del difunto Carvajal, presenta ante el Real Consejo su condición de pariente como un mérito más. Ya la Administración del Hospital se apresura a nombrarlo sustituto con carácter interino, a pesar de no haber sido oficial de la botica. Ello se interpretaba inequívocamente como un deseo explícito de los Rectores de la Casa de darle continuidad definitiva en la oficina y de esta manera era presentado a la Cámara, no ignorando la influencia que ello tendría en la decisión de provisión de la plaza.

Veintitrés años estuvo Antonio Ramos al frente de la botica, años importantes, ya que es en esa época cuando la farmacia experimenta sus más profundas transformaciones terapéuticas desde su fundación; son los años de la introducción masiva de la química, en los que se requería una sólida preparación técnica para poder asimilar los conceptos que se estaban introduciendo en la medicina, preparación que sin duda

37 AHRC. General, 1.700. 
debió poseer Ramos. Este profesional adjuntaba el título de Médico al de Boticario: de hecho, renunció a la plaza de titular de la farmacia para ejercer la medicina en el propio Hospital, continuando por ello plenamente vinculado a la Casa.

En su sustitución se dan unas circunstancias excepcionales en la casuística del Hospital e insólitas para nuestra mentalidad, pero no para la de la época, que como reminiscencia medieval admitía como lícitos ciertos derechos que transcendían al propio adquirente ${ }^{38}$. Antonio Ramos de Solís, boticario, eleva instancia a la Real Cámara de Madrid con fecha 21 de Abril de 1723 a través del Administrador D. Francisco Ignacio de Aranceaga. En ella dice que solicitó para la persona que se casase con su hija Dña. $M^{a}$ Antonia Carvajales Ramos de Solís plaza de farmacéutico, siempre que estuviese en posesión del título. Tal cosa aconteció con D. Ignacio de Arredondo Recamán, boticario examinado y aprobado que suplica se le despache Real Título.

Como vemos, ya no se trata de ser heredero carnal o político de su antecesor, sino que los derechos pasan en este caso a su hija, que por no poder ejercer tal actividad lo hará por delegación en su esposo, cuando lo tenga (en el momento de adquirir tal derecho, la hija de Ramos era soltera). En respuesta a esta petición la Cámara decide que, en efecto, tal privilegio le correspondía, aunque se había puesto como condición que antes de efectuarse el matrimonio debía comunicarse a la dicha Cámara el nombre del candidato, por ver si reunía las condiciones óptimas para el cargo de boticario del Hospital. El requisito no se cumplió, por lo cual ahora la Cámara exige a Ignacio Arredondo (ya esposo de $\mathrm{M}^{\mathrm{a}}$ Antonia Carvajales Ramos), se persone en Madrid a fin de ser evaluado. Ya vimos que se excusa de tal comparecencia alegando estar abrumado por el trabajo en la farmacia, siéndole aceptada la disculpa. Esta conclusión nos muestra hasta que punto estaba en manos de la Administración del Hospital la elección de su Ministro. La paradoja no es nimia: el candidato a la plaza soslaya el imperativo de quien ha de nombrarle para ella, alegando la necesidad de atenderla convenientemente. No se nos pasa por la mente pensar que es el candidato quien unilateralmente decide desoir el mandato de acudir a Madrid a cumplir con el requisito que la Real Cámara exige; más bien parece que es la propia Administración la que le dicta lo que conviene hacer, y no lo interpretamos como un pulso entre esta y el Real Consejo; si así fuera, la actitud de éste hubiera sido, desde luego, mucho más beligerante, al fin y al cabo en sus manos estaba la última palabra. Muy probablemente, la dirección del Hospital sabría que la alegación, planteada bajo la óptica de la muestra de una responsabilidad hacia el cargo que se pretendía, sería bien acogida por el Consejo. ¿Sutilezas del sistema?, probablemente. El respeto mutuo de competencias, la concesión a la periferia en asuntos de menor importancia, propio de un modelo de administración centralista, hacía sin duda más fácil la convivencia institucional.

\footnotetext{
38 AHRC. Cédulas Reales, 4 / 106.
} 


\section{J. SANTIAGO SANMARTÍN MIGUEZ}

Siete años después de su toma de posesión, Arredondo protagonizará un episodio único en la historia de la botica del que se da una información pormenorizada en el capítulo que dedicamos a los conflictos ${ }^{39}$. Movido por intereses profesionales al parecer más interesantes que los que le vinculan a la botica del Hospital, Arredondo hace dejación de sus obligaciones en ella hasta el punto de que la Administración del Hospital, usando de sus derechos jurisdiccionales, encarga al Alguacil de la Casa la búsqueda y captura del boticario. Luego de una serie de vicisitudes que incluyen amenazas de la Administración y nuevas ausencias mal justificadas del farmacéutico se produce su sustitución; la causa que se da es la de «dejación del cargo». Tal circunstancia no puede interpretarse como su expulsión, sino al contrario, como un abandono unilateral de las obligaciones que en su día había adquirido con el Establecimiento.

Para la sustitución de Arredondo se designa a Agustín Valero. Lamentablemente, no disponemos de información alguna que nos ilustre sobre el procedimiento y criterios para su elección, cosa que sería ciertamente interesante ya que Valero, en ese momento, estaba regentando una farmacia en Madrid ${ }^{40}$. Muchos años estuvo al frente de la botica hospitalaria, concretamente treinta y dos. A esa edad debía ser ya sexagenario y no estar en plenas facultades físicas, ya que el oficial mayor Juan García Cuervo, en 1758, en previsión de una inminente merma discapacitatoria del boticario, solicita para él la futura plaza ${ }^{41}$. La precoz solicitud obedecía a un deseo de asegurarse un nombramiento para el que había otro candidato asimismo cualificado, como vimos en su momento. Como principal argumento se hace valer el prolongado tiempo que Juan García Cuervo lleva al servicio de la farmacia en calidad de oficial y su voluntad de obtener el título que lo capacite para hacerse cargo en su momento de la dirección de la botica. La petición formulada por Cuervo parece ser atendida con prontitud ya que, según se nos informa en documentación relativa a otro asunto ${ }^{42}$, en fecha 20 de Noviembre se otorga Real Cédula en favor del auxiliar para suplir al farmacéutico en las ausencias. No obstante la fecha de su fallecimiento, acaecido en Noviembre, el titular debió estar ajeno a los asuntos de la botica desde unos meses antes ya que el último cargo de géneros adquiridos para la oficina lo firma en el mes de Febrero. A partir de esa fecha los restantes cargos hasta el mes de Octubre están sin firmar. Cuatro días después de producirse el óbito, es el oficial Cuervo quién firma la conformidad de las entregas, hasta Julio del año siguiente, en que el nuevo boticario volverá a hacerse cargo de este trámite ${ }^{43}$. Ello nos lleva a pensar que durante el tiempo de ausencia de Valero, aunque el servicio de botica lo atendiera su auxiliar y Cuervo gozara de nombramiento sustituto, la baja de Valero no tenía carácter

\footnotetext{
39 AHRC. Cédulas Reales, 510.

0 AHRC. General, 1710.

41 AHRC. Cédulas Reales, 510.

42 AHRC. Cédulas Reales, 527.

43 AHRC. Cuentas, 82.
} 
oficial. En este momento, bien sea por iniciativa del propio mancebo, o por la más probable de la Administración del Hospital, Cuervo solicita nombramiento de sustituto hasta que la plaza no esté definitivamente cubierta. Ello responde a una estrategia ya acometida en la fecha reseñada, ya que de contar con el nombramiento de sustituto interino, tendría mucho ganado para confiar en una confirmación en el cargo. El caso es que al día siguiente del fallecimiento de Valero se recibe la Real Cédula que otorga ese nombramiento ${ }^{44}$.

Tras su fallecimiento se produce la circunstancia prevista años atrás por el oficial Juan Cuervo, antes insinuada. Para la provisión de la plaza se presentan dos solicitudes, la del propio Juan Cuervo y la del hijo del boticario difunto Miguel Valero ${ }^{45}$. En ambas solicitudes los aspirantes exponen sus méritos. El hijo del difunto boticario hace valer más los adquiridos por su padre en los más de treinta años de servicio en la Casa que los suyos propios. Añade en su solicitud que tiene otros cuatro hermanos dependientes del sueldo que venía percibiendo su padre.

Por su parte, Juan Cuervo incide en las alegaciones presentadas cuando solicitó el nombramiento de suplente, con los añadidos de los méritos adquiridos desde aquella fecha.

Como sucede con ocasión de cada nombramiento, el Consejo de la Cámara solicita a la Administración del Hospital un informe relativo a los candidatos y, como siempre, será ese informe el que determine la elección. El 23 de Noviembre la Cámara solicita dichas consideraciones, que son remitidas para su consideración una semana más tarde; en ellas, D. Francisco Antonio Real, Administrador, manifiesta claramente sus preferencias, vislumbradas desde bastante tiempo atrás. De García Cuervo dice que lleva ejerciendo de oficial mayor 24 años, cargo para el que se le nombró en competencia con otros aspirantes. Informa que ha desempeñado el oficio con celo y profesionalidad, siendo hombre, en fin, de confianza, por lo que en Real Cédula de 20 de Noviembre de 1758 el Rey lo nombró suplente del boticario Agustín Valero. Añade que,

\footnotetext{
«...teniendo como tiene juntamente las demas circunstancias que previenen las reales constituciones, especialmente la 47 del Sr. Emperador Dn. Carlos Quinto, le contemplo acreedor a que S.M. se digne atenderle con el empleo vacante que pretende, pues de su eleccion no dudo redunde la creación de un Ministro aproposito para esta su Rl. Casa».
}

Hay en esta exposición un error, que por su naturaleza no se nos ocurre que haya sido fortuito: la Constitución 47 de 1524 exige para la botica un profesional examinado, con titulación, plenamente capacitado para el cargo, y Cuervo en ese momento

\footnotetext{
44 AHRC. Cédulas Reales, 527.

45 Ibidem.
} 


\section{J. SANTIAGO SANMARTÍN MIGUEZ}

carecía de tal titulación, la cual cosa extraña que ignorara el Administrador. Es más parco en el informe que da del otro aspirante, aunque igualmente diáfano:

\footnotetext{
«...de Miguel Valero, a quien conozco desde niño...poco o nada puedo informar con verdad de su suficiencia...ya que si bien de muchacho estuvo de aprendiz de la botica con su padre,...despues se ausento para mozo u oficial de la del Colegio de la Compañia de Monforte de Lemos, donde estuvo algun tiempo...».
}

Continúa diciendo que después pasó a León, donde reside actualmente; piensa el Administrador - y así lo expone - que no es aún la persona idónea para boticario del Real Hospital. Las preferencias de la Administración no dejaban lugar a dudas, por lo que la Real Cámara no precisaría, a la vista del informe, consumir mucho tiempo en deliberaciones. No obstante lo cual, surge un grave inconveniente que imposibilita el nombramiento: Juan Cuervo no está en posesión del título de boticario, entre otras cosas, porque jamás se ha examinado. Ante esta circunstancia, que tanto la Administración como el propio interesado no ignoraban sería determinante en la elección, sólo cabía solicitar una moratoria que le permitiera obtener el título de farmacéutico, o un nombramiento condicionado a dicha obtención, si bien las Constituciones, y expresamente la antes mencionada, no contemplaba esta posibilidad. Fuera cual fuera la estrategia diseñada a partir de aquel momento por Cuervo, su nombramiento pasaba necesariamente por el examen que debería pasar ante el Real Tribunal del Protomedicato. En efecto, el 12 de Enero de 1763, se recibe un escrito firmado por Andrés de Otamendi, de la Real Cámara, dirigido a D. Fco. Antonio Real en el que se dice que,

«La Camara tiene entendido que Juan García Cuervo Oficial mayor...se halla sin el examen y aprobacion que corresponde del tribunal del Protomedicato, porlo que ha extrañado que V. S. en su informe de 1 de Diciembre le acredite de habil y suficiente...». ${ }^{46}$

Por todo ello la Cámara acuerda que J. G. Cuervo se presente en el Tribunal del Protomedicato a ser examinado y aprobado, si no lo estuviere, advirtiendo que se pondrán edictos para proceder a la recepción de solicitudes. No es descabellado sospechar que la Cámara conocería la falta de titulación de Cuervo a través de un recurso presentado por su oponente Miguel Valero. Ningún dato documental nos lleva a esta suposición, pero parece extraño que el Consejo de la Cámara, de propia iniciativa haya solicitado información de examinados al Tribunal del Protomedicato. Normalmente, la Cámara realizaba el nombramiento previa presentación de determinadas credenciales —entre las que se incluían la certificación de examen-, y la correspondiente información de limpieza de sangre. Inmediatamente después de la recepción

\footnotetext{
46 Ibidem
} 
de esta comunicación, Juan Cuervo solicita certificación de práctica de boticario ${ }^{47}$. Uno de los motivos de tal solicitud podría ser la exigencia de un período mínimo de prácticas con un boticario aprobado para poder acceder al examen.

A modo de justificación de la insinuada ligereza con que el Administrador procedió a informar de la conveniencia del nombramiento de Cuervo, en escrito fechado el 26 de Enero, D. Francisco Antonio Rial responde a Otamendi:

\footnotetext{
«...es cierto que la constitucion 47 ordena que en este Hospital haya un Boticario Christiano limpio, experto y de Informacion de ello, examinado por persona de conciencia, el qual tenga a su cargo la votica: Juan García Cuervo, para poder ser admitido a la plaza de Oficial mayor de ella, fue examinado y aprobado por los Doctores Antonio Ramos Solis y D. Thomas Sanz de Velasco medicos que entonces eran de dicho Hospital...y aunque este examen y aprobacion particular...no le bastaba a Cuervo para ascender al oficio de Boticario en el Reyno ni en este Real Hospital...pero me ha bastado a mi junto con la practica de tantos años...».
}

A continuación pasa a enumerar nuevamente sus dotes profesionales, añadiendo que en el presente desempeña con satisfacción el cargo de boticario provisionalmente. Todo ello lo considera suficiente como para acreditarlo en el dicho informe. Dice además que si todavía no ha pasado el examen del Protomedicato no ha sido por falta de voluntad, sino por falta de medios — ha de mantener a 5 hijos huérfanos de la madre fallecida en accidente el 28 del pasado mes-, sin embargo, es conocedor de que ha solicitado dicho examen con urgencia. Pide disculpas por omitir en el informe dicha circunstancia, añadiendo que no tiene interés particular en el nombramiento. Salta a la vista que, siendo este interés particular o administrativo, el caso es que éste existe. No resulta difícil justificar la decidida apuesta que el Administrador hace por Cuervo. Sin duda hay que suponer la valía del oficial, contrastada por muchos años de servicio y de suplencias del titular. El hecho de ser persona conocida en la Casa sin duda pesaba mucho a la hora de la elección. Pensemos que el otro candidato, Miguel Valero, a pesar de ser persona conocida y de poseer la circunstancia siempre importante, pero mucho más en aquella época, de ser hijo del difunto boticario, llevaba bastantes años desvinculado del Hospital. Por imperativo mandato del Consejo se publicaron los edictos cuyo texto es el siguiente:

«Todos los Boticarios aprobados por el tribunal del Protho Medicato de Madrid que quieran ser pretendientes al oficio de Boticario deel Gran Hosptl. Real de Stgo. vacante por muerte de Agustín Valero, acudan en el termino de dos meses ...a la Secretaria del Rl. patronato de Castilla del Cargo del Sr. Dn. Andrés de Otamendi...».

Se añade una certificación de haberse fijado el edicto «en una tablilla pendiente que se puso en el Pórtico de la Puerta de esta Rl. Casa...», así como de haber manda-

47 AHRC. Cédulas Reales, 53 / 1.720. 


\section{J. SANTIAGO SANMARTÍN MIGUEZ}

do copia a La Coruña y a Tuy. Desconocemos, por falta de documentación, los pormenores de los acontecimientos que sucedieron a la publicación de los edictos. Juan Cuervo sin duda tuvo que desplazarse a Madrid y someterse al examen del Protomedicato. El caso es que en el mes de Julio de ese mismo año firma ya como boticario del Hospital. Juan García Cuervo tuvo una destacada presencia en la botica, estuvo veintidós años al frente de la misma, que sumados a la veintena larga en que actuó como oficial arrojan más de cuarenta al servicio de ella. Además, inauguró una dinastía de farmacéuticos que ocuparon durante tres generaciones la lista de titulares de la oficina.

\section{CONFLICTOS}

Los criterios de atención de la botica dieron lugar a esporádicos enfrentamientos entre sus titulares y los facultativos del Hospital. Las relaciones entre unos y otros fueron frecuentemente difíciles. Es un hecho, que el ejercicio médico, en su expresión terapéutica, cohabita con la especialización de otro profesional, el farmacéutico, produciéndose en numerosas ocasiones una superposición de criterios y matices técnicos, que cada uno de sus intérpretes consideran una invasión de su área de competencias. Esta vieja beligerancia, como ya se ha insinuado antes, es probablemente consecuencia de un quehacer indiferenciado en sus orígenes, que a pesar del paso del tiempo no ha conseguido, ni siquiera pretendido, soltar el rico lastre de conocimientos exigibles a la parte profesional complementaria. A esta disputada herencia se le adjunta el inevitable celo por preservar unos dudosos derechos de supremacía en el espacio común de la terapéutica y, por extensión, en el entramado de la sanidad. Tras la paulatina, y en ocasiones inconcreta, separación histórica de las disciplinas médicas y de la Farmacia, cada uno de estos colectivos va a adquirir una serie de objetivos en relación a su estatus profesional. El médico, continuador de su ancestral misión de diagnóstico y prescripción, va a exigir una supremacía en todo el edificio sanitario, supremacía que la propia sociedad no duda en otorgarle: no en vano el médico, tal como en otra parte de este trabajo se ha comentado, cubre la primera etapa en el camino del restablecimiento de la salud alterada y su concurso es insustituible en el proceso de curación. Esta preeminencia sobre el resto de estamentos sanitarios se verá plasmada en una serie de realidades, como son, su reconocimiento como hombre de ciencia, la consideración social que se le da, sus retribuciones económicas, etc.

Fijémonos por ejemplo en la legislación que relaciona a los médicos con los boticarios del Hospital: todas las Constituciones y Mandatos prevén el control del estado de la botica a través de las visitas que con diversa periodicidad deben cursar los médicos a la misma. En las dadas por Felipe II mandan esta supervisión en la 42: los Físicos de dos en dos meses deberán visitar «...la Botica de la casa, y las medizinas y 
cosas della...», facultándolos para dictaminar sobre su estado y proceder en consecuencia. Lo mismo se dice de los Cirujanos en la 44. La 48 del Boticario, contempla esta revisión de géneros en términos inequívocos: «...y que tenga los simples que entran en el compuesto, puestos por su orden como se suele hazer todo un dia para que los Medicos y Cirujano lo vean...».

Las Constituciones de Carlos V introducen una sutil novedad al dictar bajo el mismo Título - el V- las concernientes a médicos, cirujano y boticario, separadas en las anteriores. Ello puede interpretarse como el ensamblaje, en un mismo organismo operativo, de las tres cabezas de sección que se dan en el cuerpo sanitario del Hospital. En estas Constituciones se repite básicamente la disponibilidad del quehacer farmacéutico al criterio de los otros dos estamentos. En efecto, los artículos 1 y 2 inciden en las condiciones de la visita a la botica, mientras que la número 3 va más allá al disponer que «...el Administrador con la asistencia de Medicos y Cirujanos le tomen quenta (al Boticario) por menor de lo que se há gastado cada mes...».

En esta situación cualquier conato de competencia que pudiera poner en entredicho su apreciado liderazgo, lo contestará el médico con contundencia. Frente a la incuestionable preeminencia que en lo social y lo legal gozan los médicos ante el boticario, la aspiración de éste, si bien más modesta, está avalada por una empecinada vocación de trabajo y de superación. Desde la separación de cometidos que llevó a médicos y boticarios por caminos distintos, aunque paralelos, el anhelo del farmacéutico es su reconocimiento como profesional científico cualificado y especializado. Pero no son únicamente estos enfrentamientos las causas de conflicto que se presentan en relación con la botica del Hospital Real de Santiago. La propia dinámica de la misma, insertada en la relativamente compleja maquinaria del Centro y en su deficiente aparato administrativo, van a ocasionar esporádicos roces con otras secciones de la Institución. Añadamos a esto un deficiente sistema de control de las compras que, unido a la falta de rigor de los responsables de la farmacia en las tareas de burocracia interna, van a dar lugar a situaciones tensas entre el titular y la Administración. A todo ello es preciso adjuntar el siempre falible factor humano, desencadenante de algunas situaciones lamentables, alguna de cuyas muestras traeremos a colación en las líneas que siguen.

En 1714 tiene lugar un violento episodio que enfrenta al boticario Antonio Ramos de Solís con el médico Domingo Sanjurxo Arellano. La disputa, que causó gran revuelo en el Hospital, nos la narra el acta de investigación de los hechos que hasta nosotros ha llegado:

«El 15 de Marzo de 1714 , entre una y dos de la tarde, en el transito que hay desde el patio de su Sria. al de los capellanes y que llaman de entretumbas harmaron riña y pendencia, con nota y escandalo....»4

48 AHRC. Pleitos, 391. 


\section{J. SANTIAGO SANMARTÍN MIGUEZ}

El testigo que declara, enfermero, se encontraba en ese momento en la enfermería, «...a punto de hacer la visita a los enfermos, a la hora de la una, como es costumbre, habiendo fenecido el Dr. Domingo Sn. Jurxo Arellano, médico, la visita de los enfermos que tiene a su cuidado...».

Según declaración de este testigo, Arellano molestó a Ramos diciendo «...que era oficio mecánico ser boticario...» y «...que los Boticarios son criados de los Médicos...» pues es «oficio servil»; molesto por ello, Ramos increpa a Arellano preguntándole sobre quién lo había hecho médico, dada su ignorancia. Se suceden en la instrucción de esta causa los testimonios, que si bien coinciden en lo fundamental, van aportando novedades segun el momento en que se incorporan a la disputa. Un testigo declara que Arellano dijo a Ramos que el oficio de boticario se reduce a hacer lo que mandan los médicos; otro oyó decir a Arellano, refiriéndose al boticario: «...eres un mal picaro, que me la has de pagar y mas, estas escomulgado...». Este comentario viene motivado, por ser Arellano, además de médico de la casa, «clérigo presvítero». El testigo, al igual que el anterior, no vio que se hubiesen maltratado. Otro testigo más declara sin embargo haberlos visto «...desgreñados y con algunas señales de sangre aunque poca...y que Arellano llamó ladrón a Ramos...». Otro pone en boca de Arellano: «...la medicina es mas noble que cualquiera otra ciencia, que a los boticarios los tenían en su ciencia como a los notarios...», siendo la botica «...un arte servil y esclava de la medezina...», a lo que Ramos responde que la botica y su arte forman parte de la medicina, y parte por cierto imprescindible.

Aparecen en el sumario las declaraciones directas de los implicados. Arellano afirma que Ramos le arrimó contra la pared, golpeándole la cabeza contra la misma y que luego lo arrojó al suelo, declarando más adelante que Ramos le atacó sin más, mordiéndole los dedos y arañándole la cara. Como podemos imaginar, el escándalo suscitado por esta disputa debió sobrepasar el ámbito del Hospital y sería muy comentado entre las gentes de una pequeña ciudad como era entonces Santiago. Como medida cautelar tras el suceso, el Administrador decide privar de libertad al boticario Ramos. El 21 de Abril, se dicta la siguiente resolución:

«Habiendo examinado estos autos, su Señoria el Sr. D. Franco. Ignacio de Aranceaga Inquisidor Apostolico del Santo Oficio de Inquisición deste Reino y Administrador para su magestad del Rl. Hosptl....suspende, alza y levanta a los sres. dichos la Multa y Carcelaria impuesta...».

dándoles licencia para reintegrarse a su trabajo. Se desprende del texto que al igual que el farmacéutico Ramos, también el médico Arellano había recibido sanción, siendo ésta probablemente idéntica a la de aquél. Lamentablemente no se disponen de datos que permitan conocer la causa de la disputa, ni si ésta tiene su origen en una diferencia de criterio profesional o más bien esconde una rencilla de tipo personal. Tampoco el Administrador debió disponer de evidencias suficientes como para ac- 
tuar punitivamente con alguna de las partes, pues como se infiere de la resolución del 21 de Abril, el asunto se concluye con el sobreseimiento del caso.

No fue este el último conflicto que tuvo al boticario Antonio Ramos como protagonista. En 1721 vuelve a producirse un hecho escandaloso en el que se ven envueltos el dicho farmacéutico y el cirujano de la Casa, D. Juan Hernández de Nera ${ }^{49}$. Los hechos suceden el dia 5 de Noviembre de 1721 según relata el instructor del caso:

«...se le ha dado noticia que entre las ocho y nueve de la mañana ha habido en la puerta Real de esta Real Casa, cierta desazón y pendencia entre D. Antonio Ramos Solis voticario de dicho Rl. Hosptl. y D. Juan Hernández de Neira Cirujano Mayor de el y que se an puesto las manos uno a otro de que ha resultado uno y otro an salido ligeramente heridos...».

El hecho, según el mismo escrito, causa gran escándalo tanto en el Hospital como en la calle; fijémonos que la disputa se produce en la misma puerta del Hospital. En tanto se abren las oportunas diligencias se les prohíbe a ambos salir de la casa y se les impone una multa como medida cautelar. La disputa se inició por unas diferencias entre el cirujano y el boticario sobre un medicamento contenido en una redoma de vidrio y sobre el que el primero expresa dudas respecto a su calidad. Según testifica una enfermera presente en el lugar de los hechos, el boticario le dio en la cara al cirujano con la redoma, rompiéndola, lo que hizo sangrar a éste; a renglón seguido se enzarzaron en una pelea de la que les separó el botiller Pedro Suárez Liñares. Según manifestación de la enfermera, el cirujano injurió al boticario llamándole «...falsario y mal boticario...». Otra enfermera, también presente, testifica que el boticario rompió la «...dicha redoma en la cara a dicho cirujano...». En similares términos se expresan otros testigos que aportan algunos detalles más: «...dándose puñadas o cachetes...». A resultas de la pelea, «...el cirujano estuvo en cama unos diez o doce días sangrado y purgado...».

El proceso es largo, su instrucción se extiende a lo largo de casi quinientas hojas, en las que se repiten los testimonios con la descripción de los hechos que no se apartan de lo aquí apuntado. La sentencia, dictada por el Mayordomo del Hospital, D. Alejandro Chavarria y Taboada, condena al cirujano. En ella ordena se paguen a cuenta de éste las costas del proceso. La apelación posterior del condenado consigue matizar la sentencia y arroja un resultado que en parte debió satisfacerle: se le continúa responsabilizando de los gastos del proceso y al boticario se le dirige una amonestación: «...D. Antonio Ramos que de aquí en adelante se porte con los Ministros de dicho Rl. Hosptl. con toda paz, quietud y buena correspondencia...», amenazándole con proceder contra él en caso contrario, al tiempo que le condena por la pendencia ocurrida en mil reales de vellón. Sin embargo lo declara «...buen ministro integro y fiel en su ministerio de tal boticario...». Se adjunta la relación de gastos ocasiona-

\footnotetext{
49 AHRC. Pleitos, 419.
} 


\section{J. SANTIAGO SANMARTÍN MIGUEZ}

dos por Antonio Ramos como consecuencia del juicio, un total de 209 reales; se da también una valoración oficial detallada de las tasas del juicio.

Los dos altercados que acabamos de ver presentan rasgos comunes y algún matiz que los singulariza. En el segundo de los hechos tenemos certeza de la causa desencadenante; se trata de un agua sobre la que el cirujano expresa sus dudas, lo que motiva el enfado del boticario. Es significativo que en los dos hechos hay acusaciones de ineptitud profesional, lo que inmediatamente desata las agresiones físicas. En ambos casos la disputa se produce entre dos «facultativos», ya que Ramos, además de ser boticario, es médico. Si bien el enfrentamiento responde a una diferencia de criterios entre físicos y boticario, la condición de médico de éste puede suponer un agravante en el mal ambiente que parece envolver las relaciones entre ellos. De un caso similar daremos noticia un poco más adelante.

En sendos procesos el Juez parece optar por una resolución salomónica. Ello puede deberse a la falta de evidencias sobre las culpabilidades, tal como antes apuntábamos, y como consecuencia de ello, al deseo de no crear agravios que pudieran deteriorar todavía más las relaciones entre profesionales, que a esa condición, unen la de Ministros de la Casa y que como tales están obligados a una estrecha convivencia. Ignoramos que nuevas aportaciones pudieron hacerse en el recurso de apelación por el que Ramos es condenado al pago de una respetable sanción. No obstante, hay que llamar la atención de que en esa segunda sentencia se trata de diferenciar muy bien lo que es un comportamiento personal reprobable de lo que es una intachable labor profesional.

Como ya apuntábamos mas arriba, los enfrentamientos entre médicos y boticarios no cierran la lista de motivos por los que estos últimos van a ver envueltos sus nombres en asuntos conflictivos. Aunque a lo largo del presente trabajo venimos sosteniendo, en ocasiones veladamente y en otras de forma manifiesta, que la labor de los boticarios del Hospital fue en general irreprochable, a pesar de innegables desviaciones respecto de la legalidad vigente en cada momento, no se nos escapa que algunos de los profesionales de la botica constituyen en alguna de sus actuaciones excepciones a esta norma, dando muestras de ligereza en sus responsabilidades. Tal vez en este excepcional grupo podamos situar el comportamiento del boticario Ignacio Arredondo al final de su gestión al frente de la botica del Hospital ${ }^{50}$. Dicho farmacéutico, tras siete años de correcta atención de la oficina, parece estar en trance de establecerse en la villa de Pontevedra, probablemente con una farmacia de carácter privado, aunque por la documentación examinada no descartamos que le movieran otro tipo de negocios. Con motivo de ello se ausenta con cierta frecuencia del Hospital, lo que conlleva la desatención de la botica. Arredondo continuaba en el Hospital de forma

50 AHRC. Pleitos, 21. 
provisional, desinteresado ya por completo de su trabajo y deseando consumar su salida de la misma con los menores problemas posibles.

El 2 de Febrero de 1731 se le conceden doce días para ausentarse del Hospital y desplazarse a Pontevedra, «...con denegación de mas tiempo y fenecido el que va señalado...» se procederá en consecuencia; y así ocurre, ya que en Junio es definitivamente apartado de su cargo.

Hasta aquí hemos estado considerando las fuentes de conflicto que tienen por protagonista al boticario o al personal de la botica en tanto en cuanto son profesionales de la misma y en relación con hechos en ella acaecidos; otros conflictos, obtenidos de la documentación estudiada, afectarán a los boticarios de la Pía Institución, pero éstos tendrán como sujeto, no ya al profesional, sino al hombre que lo encarna y, por lo tanto, escapan ya del objetivo de este trabajo.

\section{CONCLUSIÓN}

A lo largo de los distintos apartados de este artículo hemos intercalado comentarios críticos que por sí mismos constituyen un análisis de la relación que se produce entre la legislación que ordena la vida de la botica del Hospital y la de sus profesionales con la casuística que la dinámica de la Institución engendra. Pensamos que esa inadecuada normativa es causa frecuente de los casos de tensión que se dan en el Establecimiento. Hemos intentado también situar a los boticarios del importante centro sanitario compostelano en el entramado social de su época y en el microcosmos que supone el propio Hospital. Después de recorrer, a lo largo de estas páginas, lo que fue la vida de la botica en el período estudiado, esperamos haber esclarecido la inicial afirmación de la importancia del modelo comunitario con que se concibe la vida hospitalaria —en lo profesional y en lo personal—, con la sucesión de acontecimientos que afectan a cada uno de los aspectos que conforman el presente estudio. La ocasional alusión a los profesionales de otros centros hospitalarios de parecidas características al compostelano, confiamos que haya contribuido a situar, en el contexto peninsular, la realidad de los boticarios del emblemático hospital gallego en sus diversas facetas. 